\title{
塔克拉玛干沙漠和戈壁沙尘起沙、传输和沉降 的对比研究
}



1. 兰州大学大气科学学院, 半干旱气候变化教育部重点实验室, 兰州 730000;

2. 中国气象科学研究院, 气候系统极地气象研究所, 北京 100081

*通讯作者, E-mail: hjp@1zu.edu.cn

收稿日期: 2017-01-09; 接受日期: 2017-05-10; 网络版发表日期: 2017-06-12

国家自然科学青年科学基金项目(批准号: 41405003)、国家自然科学基金创新研究群体项目(批准号: 41521004)、中央高校科研创新团队 培育项目(编号: LZUJBKY-2016-ct04)、中国高等学校学科创新引智计划项目(编号: B13045)和兰州大学半干旱气候变化教育部重点实验 室资助

摘要＼cjkstart塔克拉玛干沙漠(Taklimakan Desert, TD)和戈壁沙漠(Gobi Desert, GD)是东亚两个最主要的沙尘源区, 对 区域甚至全球的能量收支、生态系统及水循环过程都有非常重要的影响. 本文利用WRF-Chem模式(The Weather Research and Forecasting model with Chemistry) 对比研究了 2007 2011年不同季节TD和GD地区的起沙、传输以 及沉降情况, 探讨了 TD和GD地区对整个东亚地区沙尘的贡献。研究结果表明,地形、海拔高度、热力条件以 及环流条件的差异导致了两大沙源区在沙尘释放、抬升能力以及远距离输送等方面均有很大不同. GD地区地 形平坦, 海拔高度相对较高, 上空位于南北两支急流汇合处, 高空风速大, 深厚的对流混合促使高空急流下沉 支将更多的高空动量不断下传到对流层中层, 导致 GD地区中低层风力增大, 有利于 GD沙尘的垂直抬升. 因此, 在强西风急流的作用下, GD沙尘容易进行远距离输送, 是东亚地区最主要的沙尘贡献区域. 春、夏季节GD沙 尘传输量分别约占起沙量的 $35 \%$ 和 $31 \%$. TD 在东亚地区的起沙能力最强, 春季起沙通量为 $70.54 \mathrm{Tg} \mathrm{a}^{-1}$, 占东亚地 区起沙的 $42 \%$. 然而, TD地区身处盆地、三面环山, 且近地面多以东风为主, 沙漠上空风速较小, 因此 TD地区 不利于沙尘传输, 大量沙尘在扬起后又重新沉降到地表(总沉降量约为 $40 \mathrm{gm}^{-2}$ ). 只有当 $\mathrm{TD}$ 沙尘抬升到 $4 \mathrm{~km}$ 以上 才能进入西风带开始远距离输送, 对整个东亚地区沙尘的贡献相对较小, 春、夏季节 $\mathrm{TD}$ 沙尘传输量分别约占 起沙量的 $25 \%$ 和 $23 \%$.

关键词＼cjkstart东亚沙尘, WRF-Chem模式, 塔克拉玛干沙尘, 戈壁沙尘, 起沙, 传输, 沉降

\section{1 引言}

沙尘气溶胶(以下简称沙尘)是对流层气溶胶的主 要成分. 作为影响地球系统能量平衡的重要因素之一,
它不仅能够通过散射和吸收太阳辐射能直接影响地球 辐射收支系统(Jia等, 2015), 还可以通过间接影响云凝 结核和冰核来改变云反照率和寿命, 从而进一步影响 降水(Huang等, 2006a, 2006b, 2010, 2011, 2014; Qian等,

中文引用格式: 陈思宇, 黄建平, 李景金金, 贾瑞, 江南萱, 康丽泰, 马骁骏, 谢亭亭. 2017. 塔克拉玛干沙漠和戈壁沙尘起沙、传输和沉降的对比研究. 中国 科学: 地球科学, 47: 939-957, doi: 10.1360/N072016-00257

英文引用格式： Chen S Y, Huang J P, Li J X, Jia R, Jiang N X, Kang L T, Ma X J, Xie T T. 2017. Comparison of dust emissions, transport, and deposition between the Taklimakan Desert and Gobi Desert from 2007 to 2011. Science China Earth Sciences, 60: 1338-1355, doi: 10.1007/s11430-016-9051-0 
2009; Fu等, 2009; Yue等, 2010, 2013; Chen等, 2014a; Ge 等, 2010; Wang等, 2010). 东亚地区起沙量大、扩散范 围广, 作为世界上主要的沙尘源区对全球贡献了大量 的沙尘(Zhang等, 2003). 据估算, 每年大约有 $600 \mathrm{Tg}$ 的 东亚沙尘释放到大气中, 其中约 $30 \%$ 被重新沉降到沙 漠地区, $20 \%$ 被传输到中国内陆地区, 剩余的 $50 \%$ 向东 远距离传输到韩国、日本、太平洋地区, 并跨越太平 洋地区到美国、加拿大甚至格陵兰岛等地(Huang等, 2008; Kim, 2008; Eguchi等, 2009; Wang等, 2016; Chen 等, 2013, 2017; Kang等, 2016; 康丽泰和陈思宇, 2017), 如此时空规模的沙尘粒子对区域乃至全球气候与环 境都有重大影响.

塔克拉玛干沙漠(Taklimakan Desert, TD)和戈壁沙 漠(Gobi Desert, GD) 是东亚地区两个最主要的沙尘源 区(Sun等, 2001; Uno等, 2008; Zhang B等, 2008; Wang 等, 2012). 位于南疆塔里木盆地中央的 TD(图1), 面 积为 $33.76 \mathrm{~km}^{2}$, 是中国最大的沙漠, 也是全世界第二 大的流动沙漠. $\mathrm{TD}$ 位于昆仑山脉以南的塔里木盆 地, 三面为高山环绕, 北邻天山山脉, 西邻帕米尔高 原, 东西长约 $1000 \mathrm{~km}$, 南北宽约 $400 \mathrm{~km}$. 作为一个暖温 带沙漠, TD地区年平均降水不超过 $100 \mathrm{~mm}$, 最低只有 $4 \sim 5 \mathrm{~mm}$, 而平均蒸发量高达 $2500 \sim 3400 \mathrm{~mm}$, 植被极端稀 少(http://en.wikipedia.org/wiki/Taklamakan_Desert). GD 位于中国和蒙古国之间, 西接 TD, 被阿尔泰山、蒙古 大草原、河西走廊以及青藏高原环绕, 覆盖了中国北



1000180026003400420050005800

图 1 模式模拟区域及地形高度的水平分布特征 红色方框分别表示下文中重点研究区域. TD: 塔克拉玛干沙漠地 区; GD: 戈壁沙漠地区
部、西北部的部分地区和蒙古的南部等地区. 作为 一个高原沙漠(海拔910 1520m), GD温度较低(年平均 $-2.5^{\circ} \mathrm{C}$ )且变化剧烈 (最高可达 $35^{\circ} \mathrm{C}$ ), 由于喜马拉雅山脉 对印度洋水汽的阻挡作用, GD地区降水稀少, 年降水量 大约194mm(http://en.wikipedia.org/wiki/Gobi_Desert).

近年来, 科学家对 TD沙尘进行了全面、深入的研 究工作,包括TD沙尘的时空变化特征(Gong等, 2003; Ge 等, 2014、起沙释放情况(Zhang等, 2003; Shao等, 2011; Chen等, 2014b)、远距离传输(Uno等, 2008; Huang等, 2007, 2008; Zhang B等, 2008)及其辐射强迫特征( $\mathrm{Su}$ 等, 2008; Huang等, 2009, 2012)等方面的探讨. 但是对 GD 沙尘的研究却没有引起足够的重视, 研究时段也仅限 于春季. Sun等(2001)利用长时间地面沙尘观测记录发 现, 除了TD地区以外, GD地区也是东亚地区非常重要 的沙源区. Shao等(2003)通过构建沙尘暴实时预测的 数值模式发现, GD地区沙尘起沙强烈, 沙尘释放通量 可达 $5000 \mu \mathrm{g}\left(\mathrm{m}^{2} \mathrm{~s}\right)^{-1}$ 以上, 其影响范围覆盖了中国内陆大 部分地区, 在黄土高原地区可达1.6 4.3t $\left(\mathrm{km}^{2} \mathrm{~d}\right)^{-1}$. Zhao 等(2004)利用 40 年气象资料得出影响内蒙古中西部地 区沙尘暴频率的主导因子分别为大风日数、北半球极 浴面积指数、亚洲北半球极浴强度指数和下垫面条 件. Huang等(2008)利用CALIPSO卫星(Cloud-Aerosol Lidar and Infrared Pathfinder Satellite Observation)的反 演结果发现, TD地区沙尘事件频发但主要以扬沙为 主, GD地区沙尘爆发次数较少, 但强度强烈. 大量沙 尘被扬起后可抬升至 $9 \mathrm{~km}$ 高度, 并可进行远距离传输 至中国东部甚至太平洋海域.

然而, TD和GD地区沙尘的释放、传输和沉降过 程有何差异? 这些差异又是什么原因导致的? 两者对 整个东亚地区沙尘的贡献有何不同? 基于以上这些亟 待解决的科学问题, 本论文将以高性能的WRF-Chem 数值模式作为基础, 结合卫星遥感数据, 全面分析和对 比2007 2010年不同季节TD和GD地区沙尘的释放、 传输和沉降过程, 以及产生这种差异的原因, 重点探 讨两大沙源地对东亚沙尘的贡献.

\section{2 模式介绍}

WRF-Chem模式(Weather Research and Forecasting coupled with Chemistry, WRF-Chem) 是当今国际上发展 比较成熟的空气质量模式, WRF-Chem模式在WRF模 
式的基础上加入了气相化学机制、光分解方案和气 溶胶机制等各种参数化方案, 考虑了气溶胶排放、形 成以及输送(包括平流、扩散和对流过程)和干湿沉降 等过程, 也考虑了气相化学、气溶胶形成、辐射和光 分解率、气溶胶参数化和光分解等化学过程. 与其他 数值模式相比, WRF_Chem模式的优越性主要在于真 正实现了气象模式与化学模块在时间和空间分辨率 上的完全在线耦合, 可以很好体现气溶胶和气象场的 相互反馈(Grell等, 2005).

本章采用的气溶胶模块是MADE/SORGAM(Modal Aerosol Dynamics Model for Europe with Secondary Organic Aerosol Model, MADE/SORGAM), 该模块耦合 了RAM2(Regional Acid Deposition Model2, RAM2)光 化学反应机制, 采用三个对数正态分布模态(3-mode), 即爱根核模 (Aitken)、积聚模 (Accumulation)和粗模 (Coarse), 来描述整个气溶胶粒子的尺度分布; 气溶胶 光学特性的描述请详见Fast等(2006).

目前, 根据不同的假设和简化方式, 国内外将起沙 参数化方案分为 3 类: (1) 经验性起沙参数化方案; (2) 基于简化起沙物理过程的参数化方案; (3) 基于详细 起沙微物理过程的参数化方案 (Zender等, 2003). GOCART参数化方案根据垂直沙尘通量和风速的经验公 式, 直接计算各个粒径的起沙通量, 现已被广泛应用 到全球(Ginoux等, 2001, 2004; Huneeus等, 2010)和非 洲(Cavazos-Guerra和Todd, 2012)、北美(Zhao等, 2010, 2013)等局地起沙的数值模拟研究中, 均体现出较好 的起沙模拟能力(Huneeus等, 2010). Cavazos-Guerra和 Todd(2012)使用WRF-Chem模式模拟了西非季风爆发 期撒哈拉地区的起沙过程. 通过与多种地面和卫星 对比验证, 发现该参数化方案能够较好再现撒哈拉 沙尘起沙的主要特征. Weaver等(2002)使用GOCART 模式和辐射传输模式计算了撒哈拉地区沙尘的短 波和长波辐射强迫, 并通过与Earth Radiation Budget Experiment(ERBE)和 Total Ozone Mapping Spectrome-

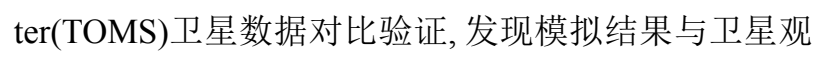
测较为吻合. Zhao等(2010)在WRF-Chem模式中采用 两种起沙方案(GOCART和DUSTRAN)和两种气溶胶 模块(MADE/SORGAM和MOSAIC)讨论了它们对北非 沙尘及其辐射强迫的不确定性. 研究表明, 两种起沙方 案可以得到比较一致的起沙时空分布特征, 但在局部 地区模拟的起沙通量有较大差异. 此外, GOCART起沙
参数化方案不仅可以很好抓住东亚主要沙尘源区 TD 和 $\mathrm{GD}$ 的起沙强度变化及其沙尘浓度的时空演变特征, 对沙尘源地附近及下游地区地面沙尘浓度时间变化特 征的模拟也与站点观测结果十分接近(Chen等, 2013, 2014b, 2017). Cheng等(2012)在研究中国地区AOD长 期变化特征中发现, GOCART模式结果与AERONET 观测资料具有较好的一致性. GOCART起沙参数化方 案的具体形式如下:

$$
G=C S_{p} u_{10 \mathrm{~m}}^{2}\left(u_{10 \mathrm{~m}}-u_{t}\right),
$$

式中, $C$ 是起沙因子, 是一个高度可调的经验常数,一般 需要通过卫星观测的气溶胶光学厚度来进行调整, 具 有较大的不确定性. 我们利用2007 2011年MODIS、 MISR卫星反演得到东亚地区的AOD与模拟结果进行 对比验证, 发现当起沙因子 $C=1$ 时该起沙模块即可很 好模拟出沙尘源区附近沙尘气溶胶的空间分布特征, 尤其对塔克拉玛干沙漠和戈壁沙漠的沙尘时空分布特 征均表现出良好的模拟效果(Chen等, 2014b). 为了控 制起沙的范围, GOCART起沙参数化方案中给出了风 蚀度指数 $S$. 该指数是一个基于地形起伏变化并结合了 植被覆盖和雪盖等地表参数得到的因子, 定量表征了 一个网格内能起沙的网格面积所占的比列即潜在沙源 地. 从图 2 中可以发现, 两大沙漠的风蚀度指数 $S$ 可以 很好反映两大沙尘源区的潜在沙源区, 与东亚真实沙 漠分布有非常好的一致性(Nakano等, 2004; Kanayama 等, 2005; Wang等, 2016). 沙源主要分布在中国西北地 区以及中蒙交界附近, 其中最大的沙漠是位于中国新

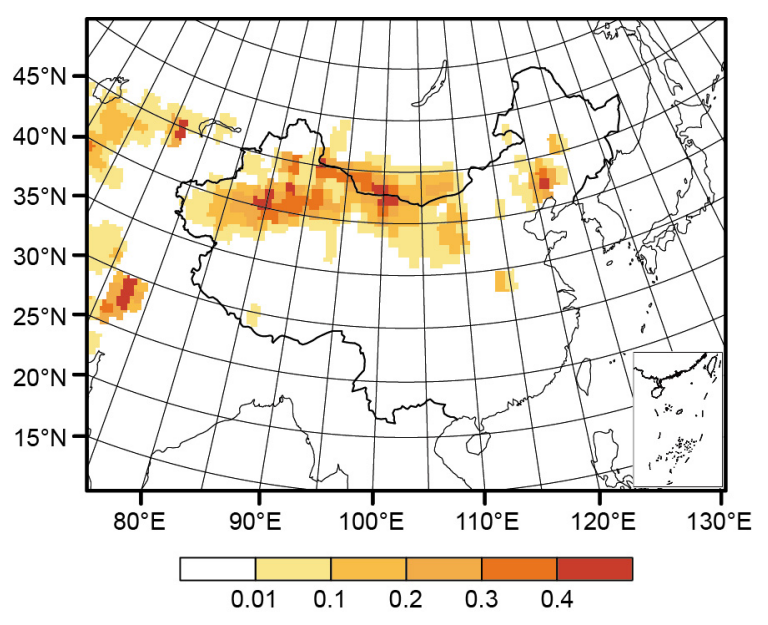

图 2 东亚地区风蚀度指数的空间分布特征 
疆自治区南部塔里木盆地的塔克拉玛干沙漠(TD)和 中国内蒙古自治区-外蒙古一带的戈壁沙漠(GD). 其 中, 塔克拉玛干沙漠以沙粒为主, 戈壁沙漠则为沙粒、 砂质粉土和黏土的混合(图略). 因此, 塔克拉玛干沙 漠的风蚀度指数普遍高于戈壁沙漠. 此外, $u_{10 \mathrm{~m}}$ 是地 面 $10 \mathrm{~m}$ 的水平风速; $u_{t}$ 为地面 $10 \mathrm{~m}$ 的临界风速, 是粒子 尺度, 空气密度和土壤湿度的函数. Ginoux等(2004)假 设 $u_{t} \sim u_{*}$, 其中 $u_{*}$ 为临界摩擦速度, 采用 Marticorena和 Bergametti(1995)公式计算并考虑土壤湿度的影响, 其 公式如下:

$u_{t}=\left\{\begin{array}{l}A \sqrt{\frac{\rho_{p}-\rho_{a}}{\rho_{a}} \mathrm{~g} \Phi_{p}}\left(1.2+0.2 \log _{10} w\right) \text { if } w<0.5, \\ \infty \text { otherwise, }\end{array}\right.$

式中, $A=6.5$, 为粒子尺度; $\rho_{p}$ 和 $\rho_{a}$ 分别为粒子密度和空 气密度; $\Phi_{p}$ 为粒子直径; $\omega$ 为地表湿度, 取决于降水、 蒸发以及土壤的持水性等, 范围从 $0.001 \sim 1$, 在雨后会 高于 0.5. Belly(1964)和Pye(1989)认为决定 $u_{t}$ 的主要因 素是粒子间的相互作用力, 与粒子尺度和土壤湿度有 很大关系. 申彦波等(2005)利用Shao方案, 结合敦煌地 区的实际观测资料, 得到 $u_{t}$ 随地表土壤水分含量和植 被覆盖度的增大而增大. 但是, 东亚主要沙源区集中 在海拔 $1500 \mathrm{~m}$ 以上的中纬度沙漠地带, 年降水量非常 低, 且大部分沙尘天气都出现在干燥少雨的春季, 土 壤湿度对沙尘起沙的影响并不会太大.

本文所使用的参数化方案设置、模式时间和 模拟区域均与 Chen等 $(2014 b, 2017)$ 相同. 目前, 耦 合GOCART起沙模块的WRF-Chem模式的模式验证 工作目前仅针对于北美和非洲等地(Zhao等, 2010). WRF-Chem模式对东亚沙尘的模拟水平还没有得到系 统、深入地了解. Chen等(2014b)结合多种先进的地面 观测(包括AERONET反演得到的AOD, 地面观测得到 的气溶胶粒子尺度分布和MPL反演得到的气溶胶垂 直结构等) 以及卫星遥感数据, 已对WRF-Chem模式对 2007 2011年东亚沙尘的模拟性能进行细致、深入的 对比验证工作, 并选择一套适合于东亚沙尘模拟的参 数化方案. 其研究结果表明, WRF-Chem模式可以很好 地描述东亚地区气象场及其东亚沙尘特别是沙尘源 区的时空分布特征及其沙尘垂直结构, 也可以较好描 述沙尘源区附近沙尘粒子谱分布的双峰结构及其季 节变化特征. 为进一步研究塔克拉玛干沙漠和戈壁沙
漠沙尘起沙、输送及其沉降的对比研究工作提供了 科学基础和有力信心. 本文在模式验证方面仅对比验 证了不同季节 $500 \mathrm{hPa}$ 风场和气溶胶光学厚度(Aerosol Optical depth, AOD)的空间分布特征.

在本次数值试验中, WRF-Chem模式的水平分辨 率为 $36 \mathrm{~km} \times 36 \mathrm{~km}$, 从地面到 $10 \mathrm{hPa}$ 共设 35 个垂直层. 模 式模拟范围为 $10.7^{\circ} \sim 59.8^{\circ} \mathrm{N}, 51.6^{\circ} \sim 154.4^{\circ} \mathrm{E}$, 格点数为 $138 \times 187$ (图1). 模式积分的初始场采用 NCEP/FNL(National Center for Environmental Prediction final analysis, $\mathrm{NCEP} / \mathrm{FNL}$ )再分析资料, 水平分辨率为 $1^{\circ} \times 1^{\circ}$, 时间间 隔为6h. 模拟时间为2006年6月1日到2011年12月31日, 为了减少模式初边界条件的不稳定性, 分析部分仅选 取 2007年1月 1 日到2011年12月 31日(以下简称模拟时 段)的沙尘模拟结果. 为了使模拟结果更好地接近于 真实大气的大尺度环流场, 本实验中采用张驰法每六 小时将模式中行星边界层以上的风场 $u 、 v$ 分量和温 度场向再分析资料逼近一次(Stauffer和Seaman, 1990). 在数值试验中 $\mathrm{CO} 、 \mathrm{NO}_{2} 、 \mathrm{SO}_{2}$ 、挥发性有机化合物 $(\mathrm{VOCs}) 、$ 黑碳(BC) 和有机碳 $(\mathrm{OC})$ 等人为气溶胶也均 被考虑在内. 数值模式中本试验使用YSU(Yonsei University Planetary Boundary Scheme, Hong等, 2006)边界 层方案、Noah陆面过程方案(Chen和Dudhia, 2001)、 Morrison 2-moment微物理方案(Morrison等, 2005)、 Kain-Fritsch积云参数化方案(Kain, 2004)以及RRTMG 长波和短波的辐射反馈方案(Zhao等, 2010). 关于数值 试验的具体设置和详细介绍请见Chen等(2014b, 2017).

\section{MISR卫星简介}

多角度光谱成像仪 (Multi-angle Imaging Spectro radiometer, 以下简称MISR) 是搭载于 Terra卫星上的 一个重要仪器. 该仪器有九个独立的照相机, 分别在 $0^{\circ}$ (天底) 以及卫星与地面垂直方向前后夹角为 $\pm 26.1^{\circ}$ 、 $\pm 45.6^{\circ} 、 \pm 60.0^{\circ}$ 和 $\pm 70.5^{\circ}$ 进行观测, 可以覆盖 $360 \mathrm{~km}$ 宽 的地表条带范围, 可以保证 9 天时间的观测能够覆盖 地球表面. 每个照相机有 4 个通道, 分别为 $0.446 \mu \mathrm{m}$ (蓝 光)、 $0.558 \mu \mathrm{m}$ (绿光)、 $0.672 \mu \mathrm{m}$ (红光)和 $0.867 \mu \mathrm{m}$ (近红 外)(Martonchik等, 2002, 2004). 由于MISR使用不同角 度的观测信息来确定地表贡献, 能有效地剔除地面反 射的太阳辐射, 基于地表反射的空间对比度利用正交 函数形式描述地表反照率, 不依赖于各波段地表反照 
率之间的假设, 因此MISR在陆地上空特别是亮地表上 空反演气溶胶有较好的表现(Diner等, 2005, 2012; Kahn 和 Gaitley, 2015; Tesfaye等, 2011; Zhang 和Reid, 2010). 相关研究表明, MISR卫星反演和地面观测的AOD在 中国地区呈现很好的一致性(Cheng等, 2012).

\section{4 结果和讨论}

\section{1 模式验证}

为了验证WRF-Chem模式对东亚沙尘的模拟能力, 本文首先利用 $\mathrm{NCEP} / \mathrm{FNL}$ 再分析资料与模式模拟的环 流场特征进行对比验证. 由于数值实验采用张驰法每 六小时将模式中行星边界层以上的风场 $u, v$ 分量和温 度场向再分析资料逼近一次, 所以数值模拟的气象场 和再分析资料的结果十分一致. 图3给出了2007 2011 年不同季节NCEP/FNL再分析资料和WRF-Chem模式 模拟的 $500 \mathrm{hPa}$ 风场的水平分布特征. 从图中可以看 出, $500 \mathrm{hPa}$ 风场的模拟结果很好地重现了再分析资料 的风场分布特征, 其中副热带西风急流和副极地西风 急流的位置和强度都和NCEP/FNL再分析资料保持一 致. 东亚大部分地区处于西风带势力范围内, 风速有 十分明显的季节变化. 春季和冬季 $500 \mathrm{hPa}$ 风速较大, 由于青藏高原地区的地形强迫, 西风带气流发生绕流 而产生南北两个分支, 在青藏高原东北部汇合并产生 较大的风速, 尤其冬季西风带的西风加强作用最为显 著. 夏季 $500 \mathrm{hPa}$ 风速最小且整个西风急流北移到青藏 高原以北的区域. 同时, 本文还比较了 NCEP/FNL再分 析资料和WRF-Chem模拟的季节平均温度场的水平分 布特征. 研究结果表明, WRF-Chem模式可以很好模 拟出东亚地区 $500 \mathrm{hPa}$ 温度槽脊的位置、形状及其深 浅(图略). 此外, Chen等(2014b)利用WRF-Chem模式的 数值模式结果和地面观测站点比较了 TD和GD地区在 2007 2011年地面风速的月变化特征. 研究表明, WRF 模式可以有效模拟地面风场的水平空间分布特征, 但 普遍高估了地面风速1 2 $\mathrm{ms}^{-1}$. WRF模式对近地面风速 的模拟误差问题普遍出现在WRF模式的模拟结果中, 其原因可能是NCEP/FNL作为模式初始场本身就存在 误差所导致的, 也可能由于WRF模式对模拟局地湍流 过程以及非均匀下垫面的次网格尺度参数化过程的 局限性所导致的(Hanna等, 2000). 尽管与地面观测相 比, 塔克拉玛干沙漠和戈壁沙漠地区近地面 $10 \mathrm{~m}$ 风速
的模拟结果系统性偏高, 但在沙尘源区再分析资料、 模拟结果和地面观测的 $10 \mathrm{~m}$ 风速随时间的变化规律非 常一致(Chen等, 2014b). 可以认为, 在起沙模块中模拟 的地面风速会整体高估起沙通量值, 但不会对模拟起 沙的时空分布特征造成严重影响. 针对数值模式关于 地面风速的这种系统性偏差, 我们通过改变GOCART 起沙方案中的经验参数 $\mathrm{C}$ 来调整起沙通量数值的大小, 减少地面 $10 \mathrm{~m}$ 风速系统性偏高所带来的模拟误差. 通 过结合大量地面观测、卫星遥感和再分析资料的对 比验证发现, 通过调整经验参数 $C$, WRF-Chem模式无 论是从起沙数值大小还是时空分布特征来看, 模拟效 果都是十分良好的(Chen等, 2014b, 2017).

为了检验模拟时段中WRF-Chem模式对沙尘光学 特性的模拟性能, 图4给出了MISR卫星反演以及模式 模拟的东亚地区2007 2011年季节平均的550nm AOD 的空间分布特征. 为了更好地和观测结果作对比, 模式 结果与卫星过境时间及其有效数据点完全匹配. MISR 反演的不同季节AOD在分布形式和数值大小上存在 一定差异. 在春、夏季节, TD和GD地区均是AOD的大 值中心, 平均值大于 0.45 . 由于人为污染物的存在, 中 国东部地区和四川盆地也存在一个AOD大值区, 夏季 $\mathrm{AOD}$ 的平均值可达 0.65 以上. 在秋、冬季节, 整个东亚 地区的AOD大幅度减弱, TD和GD AOD的平均值减小 至 0.25. WRF-Chem模式可以很好再现东亚气溶胶的 空间分布特征及其季节变化规律. 两大沙漠的沙尘气 溶胶光学厚度对AOD的贡献可达 $95 \%$ 以上(图略). 模 式模拟的TDAOD比卫星反演的略高, 这种差异在夏季 更为显著, AOD高值区可达0.7. Chen等 $(2013,2014 b)$ 的研究结果也表明, WRF-Chem模式可以很好描述东 亚两大沙源区 (TD 和 GD) 沙尘气溶胶的年变化和季节 变化特征, 仅对夏季和秋季在TD AOD有所高估. 我们 认为, 近地面 $10 \mathrm{~m}$ 风速的模拟误差以及GOCART起沙 模块不能很好地描述沙尘释放通量的季节变化可能 是导致模拟误差的主要因素. 在模拟区域的左下角, 卫星反演得到的AOD要高于模拟结果, 说明模式对该 区域人为气溶胶排放源的估计偏低. 但由于我们在本 文中仅关于沙尘气溶胶, 所以不在本文讨论的范畴中. 总体来说, 模拟结果可以较好反映东亚地区的气象场 特征特别是沙尘气溶胶的时空分布特征, 为本文后面 的讨论提供了有力的科学基础. 下面将针对 TD和 GD 沙尘释放、传输和沉降过程, 以及产生这种差异的原 

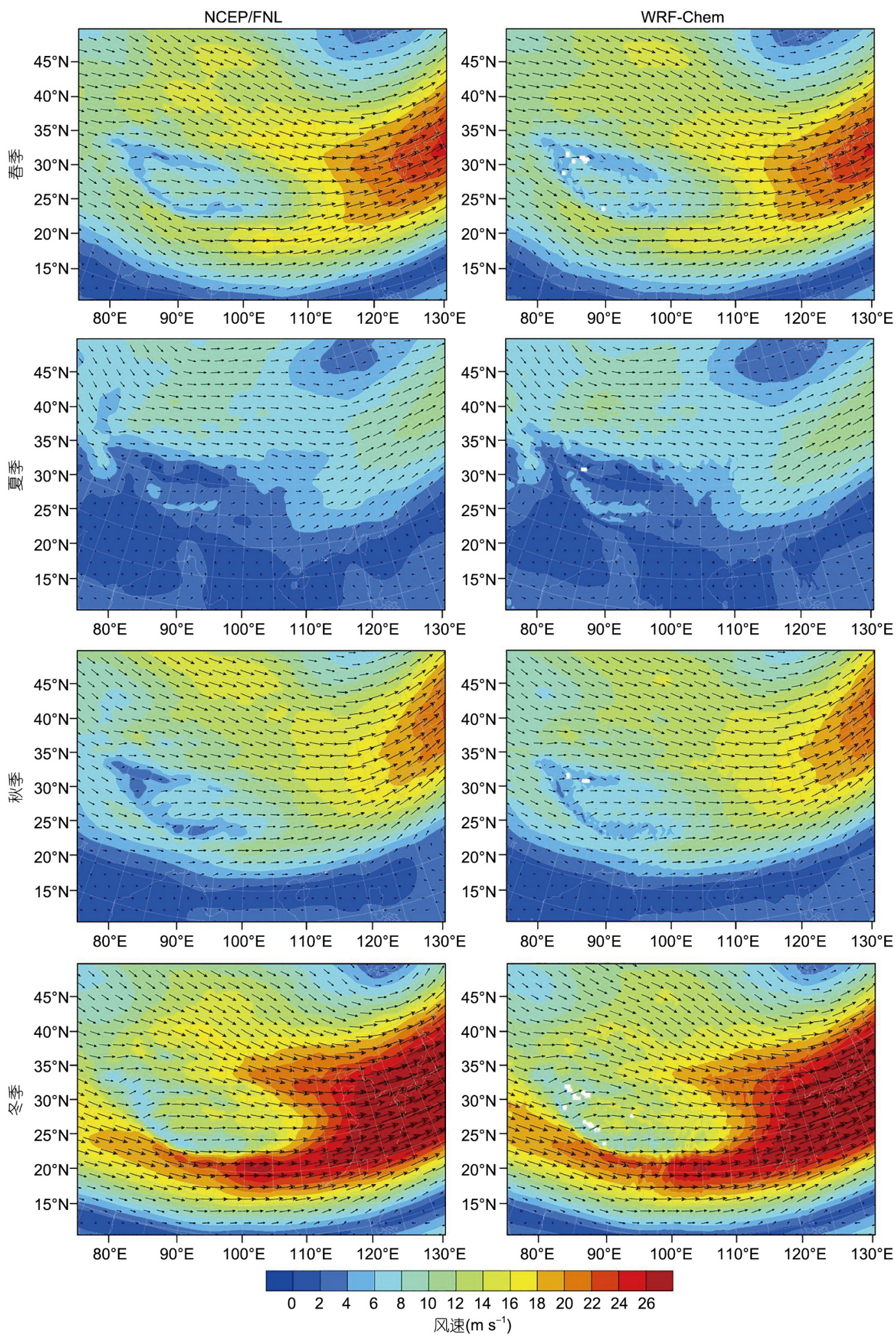

图 32007 2011 年不同季节 NCEP/FNL 再分析资料和WRF-Chem 模式模拟得到的 $500 \mathrm{hPa}$ 风场的水平分布特征 颜色阴影代表风速, 箭头代表风向 

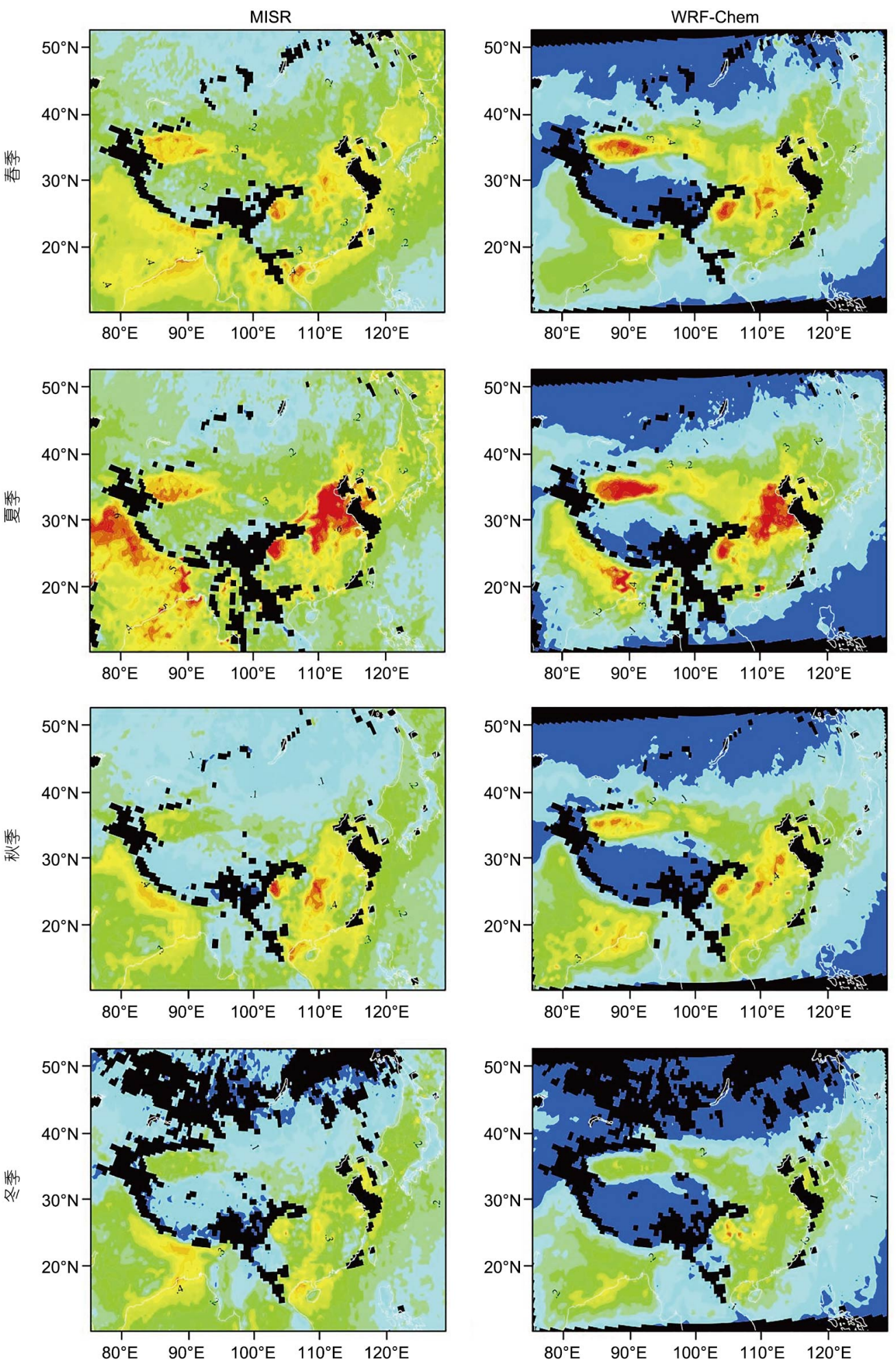

$550 \mathrm{~nm}$ AOD

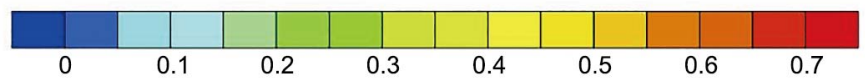

图 42007 2011年不同季节MISR卫星反演及WRF-Chem模式模拟的东亚地区550nm AOD的空间分布特征 
因做具体讨论.

\subsection{TD和GD地区的沙尘释放}

首先, 我们对比分析了 TD和GD地区在不同季节的 沙尘起沙情况. 表1给出了2007 2011年 TD $\left(75^{\circ} \sim 95^{\circ} \mathrm{E}\right.$, $35^{\circ} \sim 45^{\circ} \mathrm{N}$ ) 和 GD地区 $\left(95^{\circ} \sim 110^{\circ} \mathrm{E}, 35^{\circ} \sim 40^{\circ} \mathrm{N}\right)$ (图 1)季节 平均的沙尘年释放量及其对整个东亚地区(图1)沙尘 年释放量的贡献. 从表中可以看出, TD和 GD两大沙 漠的起沙量之和对整个东亚地区的贡献可高达 $75 \%$, 说明位于中国西部的TD和中国北部至蒙古境内的 GD 是东亚两个最主要的沙尘源区. TD和GD地区的沙尘 释放量在春季均达到最大, 分别是 70.54 和 $64.87 \mathrm{Tg} \mathrm{a}^{-1}$, 约占整个东亚地区起沙释放量的 $38.9 \%$ 和 $35.8 \%$. 在夏 季, $\mathrm{TD}$ 和 $\mathrm{GD}$ 地区沙尘释放量的差异最为显著, 沙尘释 放量分别为 58.76 和 $40.68 \mathrm{Tg} \mathrm{a}^{-1}$. 在秋、冬季, 两大沙漠 的起沙能力均显著减弱, $20 \sim 40 \mathrm{Tg} \mathrm{a}^{-1}$, TD地区的沙尘 年释放量小于 $\mathrm{GD}$, 但两大沙漠的总起沙量仍占整个 东亚起沙量的 $60 \%$ 以上. 图5给出了 TD和GD沙尘释放 量在不同季节所占的比例. 从图中可以发现, 春、夏 两季 TD和 GD地区起沙量最大, 分别占全年释放总量 的 $69 \%$ 和 $59 \%$. TD地区在不同季节沙尘释放比例不均 匀性较高, 春、夏季节和秋、冬季节相差悬殊. 与 $\mathrm{TD}$ 相比, GD地区在四个季节中沙尘释放比例相对较为 均匀, 秋季起沙比例最小, 约占全年的 $20 \%$. 图6给出了 2007 2011年不同季节东亚地区地表沙尘浓度的空间 分布特征, 说明地表沙尘浓度与起沙通量的空间分布 特征有很好的一致性. 东亚地区沙尘地表浓度的高值 中心分别在TD和GD. 在春、夏季, TD地区的地表沙 尘浓度最高, 平均值约为 $0.8 \mathrm{mg} \mathrm{m}^{-3}$, GD地区略低(平均 值约为 $0.76 \mathrm{mg} \mathrm{m}^{-3}$ ). 在秋季和冬季, GD地区的地表沙

\section{表 12007 2011年塔克拉玛干沙漠和戈壁沙漠地区(图} 1)季节平均的沙尘释放量 ${ }^{a}$

\begin{tabular}{ccc}
\hline & 塔克拉玛干沙漠 $\left(\mathrm{Tg} \mathrm{a}^{-1}\right)$ & 戈壁沙漠 $\left(\mathrm{Tg} \mathrm{a}^{-1}\right)$ \\
\hline 春季 & $70.54(38.9 \%)$ & $64.87(35.8 \%)$ \\
夏季 & $58.76(41.8 \%)$ & $40.68(28.9 \%)$ \\
秋季 & $33.34(33.2 \%)$ & $36.13(35.9 \%)$ \\
冬季 & $24.67(26.0 \%)$ & $38.02(40.1 \%)$ \\
\hline
\end{tabular}

a) 括号中的百分比表示塔克拉玛干沙漠和戈壁沙漠占整个 东亚地区(图1)沙尘释放量的比例 (a) TD

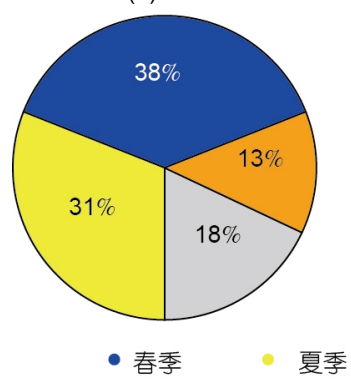

(b) GD

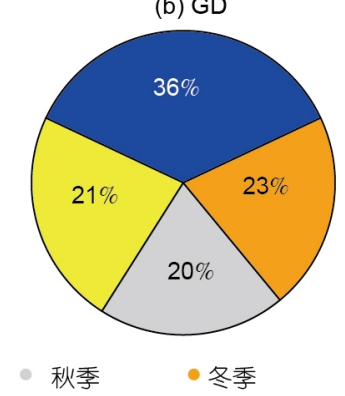

图 5 2007 2011年塔克拉玛干沙漠和戈壁沙漠地区沙尘 释放通量在不同季节的比例

尘浓度较高, 最高值可达 $1.1 \mathrm{mgm}^{-3}$.

沙尘起沙量可以很好反映沙尘的起沙能力. 然而 当沙尘大量释放后, $\mathrm{TD}$ 和 $\mathrm{GD}$ 上空的沙尘含量是否与 该地的起沙情况相一致? 图7分别给出了 2007 2011年 $\mathrm{TD}$ 和 GD上空3 10 km 的月平均沙尘浓度(图7a)及其 $\mathrm{TD}$ 和 $\mathrm{GD}$ 上空3 10km沙尘浓度与 $3 \mathrm{~km}$ 以下沙尘浓度的比 值(图7b). 从图7a中可以看出, 沙源上空沙尘含量的年 际变化不显著. 3 10km高度的TD沙尘含量普遍高于 GD地区, 这种差异在3 9月份(春季和夏季)表现尤为 明显, 其他月份两个地区3 10km沙尘含量基本一致, 这主要是TD在春、夏季的起沙量普遍大于 GD所导致 的. 有趣的是, 从3 10km沙尘浓度与 $3 \mathrm{~km}$ 以下沙尘浓 度的比值中可以发现(图7b), 相比于 TD地区, 春季和 夏季GD地区起沙量较小, 但GD沙尘在 $3 \sim 10 \mathrm{~km}$ 高度范 围内所占的比例更多, 尤其在夏季该比例可高达 $80 \%$, 说明GD沙尘在春、夏季节(尤其是夏季)可将更高比 例的沙尘抬升到沙源上空. 从TD和GD 8 10km高空的 沙尘含量(图8)可以进一步发现, GD和TD地区在这个 高度范围内的沙尘含量相当. GD地区 $8 \sim 10 \mathrm{~km}$ 沙尘浓 度与 $3 \mathrm{~km}$ 以下沙尘浓度的比值可达 $11 \%$. 由此可知, 两 大沙源的起沙情况与其上空的沙尘含量存在着一定 的不一致. 尤其在夏季, GD地区虽然起沙量较小, 但 更容易将沙尘抬升至较高的高度.

为了探究其原因, 我们进一步给出了 $\mathrm{TD}$ 和 GD两 个地区不同季节纬向平均的沙尘浓度和位温的垂直 分布特征(图9). 从图中可以发现, 两个沙源区的沙尘 一般积聚在 $5 \mathrm{~km}$ 以下, 高值区在 $1.5 \mathrm{~km}$ 以下, 沙尘浓度 可达 $400 \mu \mathrm{g} \mathrm{m}^{-3}$ 以上. 随着高度增加, 沙尘浓度迅速减 小, 最高可超过 $9 \mathrm{~km}$. TD是一个明显的热源, 该地区上 

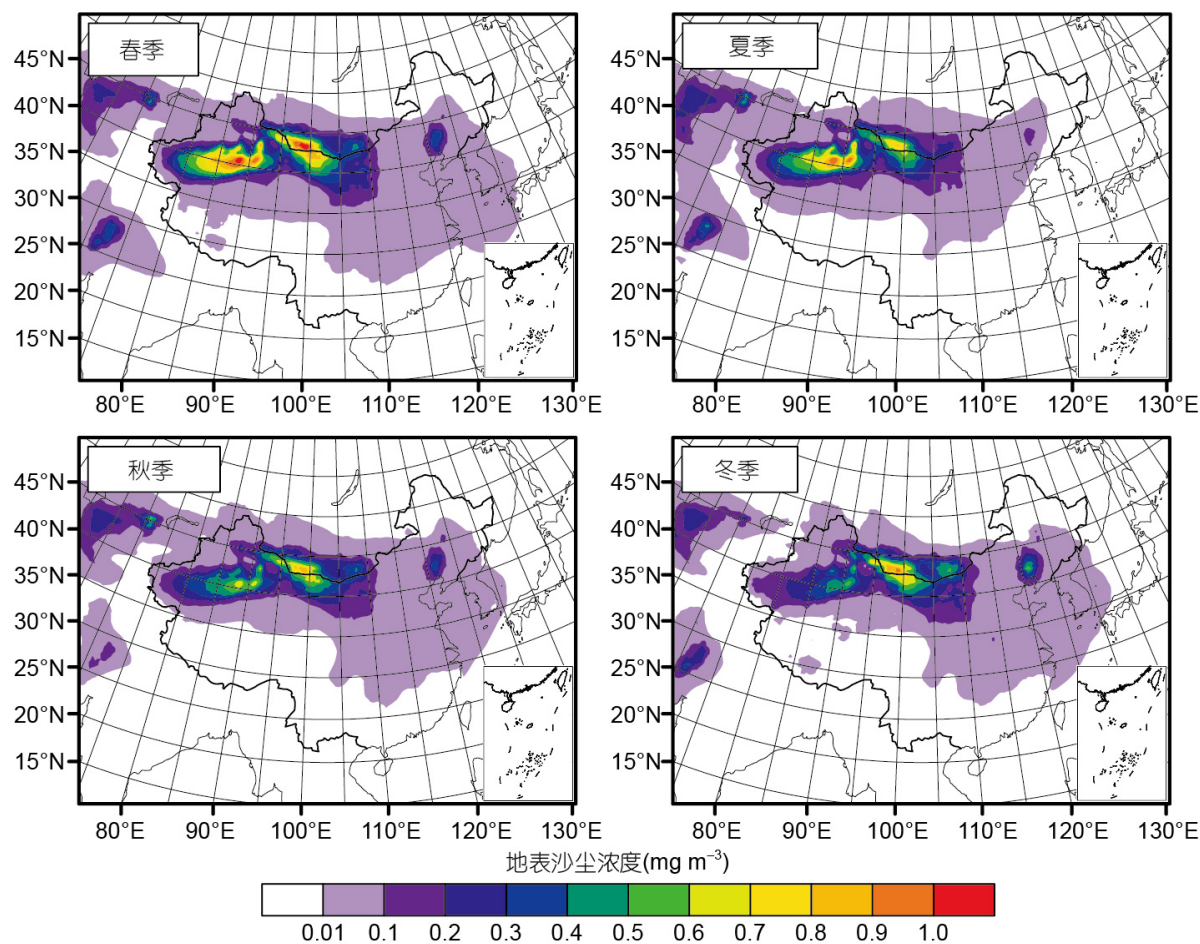

图 62007 2011年不同季节东亚地区地表沙尘浓度的空间分布特征
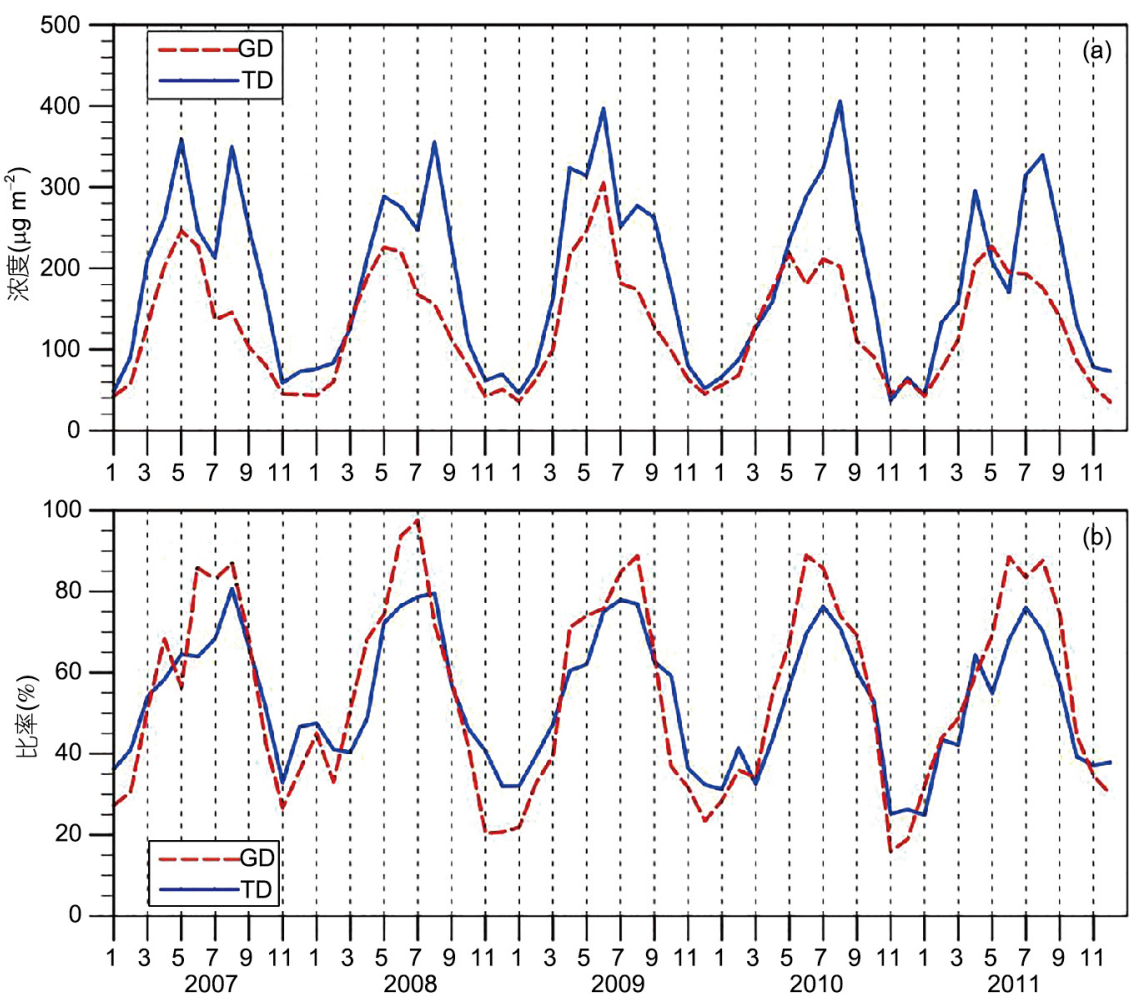

图 72007 2011年 TD和 GD 上空3 10 km 的月平均沙尘浓度(a)及其与 $3 \mathrm{~km}$ 以下沙尘浓度的比值(b) 

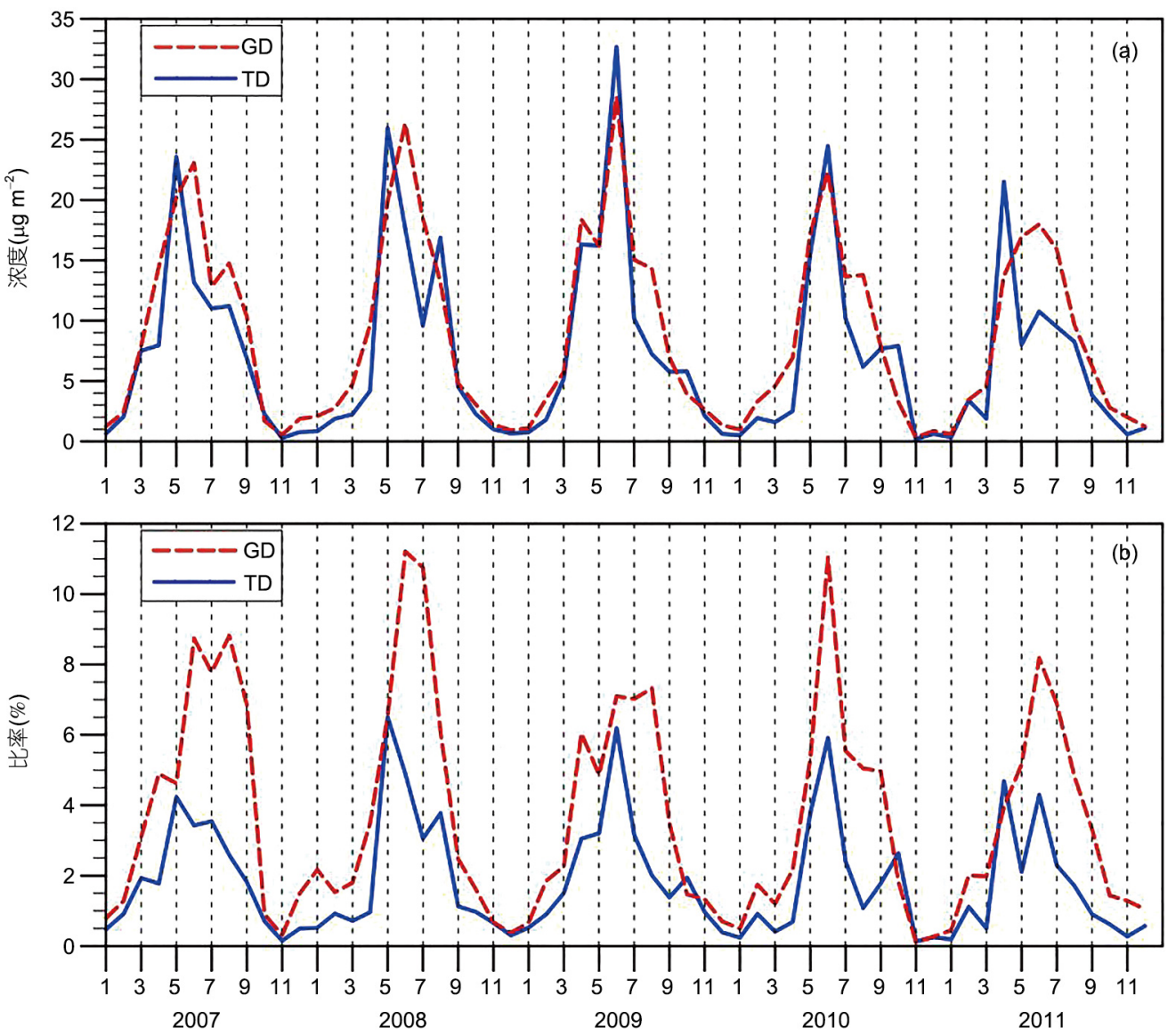

图 $82007 \sim 2011$ 年 TD和 GD 上空 8 10 km 的月平均沙尘浓度(a)及其与 $3 \mathrm{~km}$ 以下沙尘浓度的比值(b)

空的位温等值线较为密集, 说明受热力作用的影响, 位温随垂直高度增加显著, 大气层结较为稳定, 春季 的沙尘层被控制在272 284K. 与 TD地区相比, GD地 区低层大气(小于 $3 \mathrm{~km}$ )的沙尘浓度小于 TD. 然而, TD 和 GD 上空(大于 $5 \mathrm{~km}$ ) 的沙尘浓度相当. 尤其在夏季, GD地区的下垫面温度分布不均匀, 大气斜压性容易 产生向南的热成风; 此外, GD位温等值线分布相对较 稀疏, 温度梯度小, 垂直方向混合强烈, 热力湍流发展 旺盛, 有利于更多沙尘抬升至高空, 沙尘层主要被控 制在280 292K. 图 10进一步给出了2007 2011年不同 季节 $42^{\circ} \mathrm{N}, 75.3^{\circ} \sim 120.2^{\circ} \mathrm{E}$ 范围内 $\mathrm{U}$ 分量的垂直分布特 征. 从图中可以发现, TD近地面主要以东风为主, 地 面风速大, 大量沙尘被扬起后, 高空风速相对较小, 加 之海拔高度低以及复杂地形等诸多不利因素的限制, 导致TD沙尘不利于进一步的抬升和传输. 在GD地区, 其地面风速较小, 起沙量相对较小. 但GD高空受西风
急流的影响大, 受该地热力条件的配合(图9), 深厚的 对流混合促使高空急流下沉支将更多的高空动量不 断下传到对流层中层, 导致GD地区中低层风力增大, 从而进一步加强GD沙尘的垂直抬升能力. 其次, 作为 一个海拔在910 1520m的高原沙漠, 其地理条件也为 GD沙尘抬升到一个较高的高度提供了有利条件.

\subsection{TD和GD地区的沙尘传输}

起沙是讨论沙尘过程的重要部分, 不同沙尘源区 沙尘的起沙量虽然可以提现沙尘的起沙能力, 但由 于沙尘传输和沉降的复杂性, 沙尘源区的起沙量和沉 降区的沙尘浓度不是简单的线性关系. 因此, 我们有 必要对TD和GD的沙尘传输情况进行对比分析, 进而 探讨两个沙源地影响东亚沙尘的差异. 图 11给出了 2007 2011年不同季节两大沙尘源区沙尘释放和传输 的季节变化趋势. 从图中可以发现, 不同季节的GD沙 



图 92007 2011年不同季节 TD(左)和 GD(右)纬向平均的沙尘浓度和位温的垂直分布特征 颜色阴影代表沙尘浓度, 单位: $\mathrm{mg} \mathrm{m}^{-3}$; 虚线代表位温, 单位: $\mathrm{K}$ 
(a) 春季
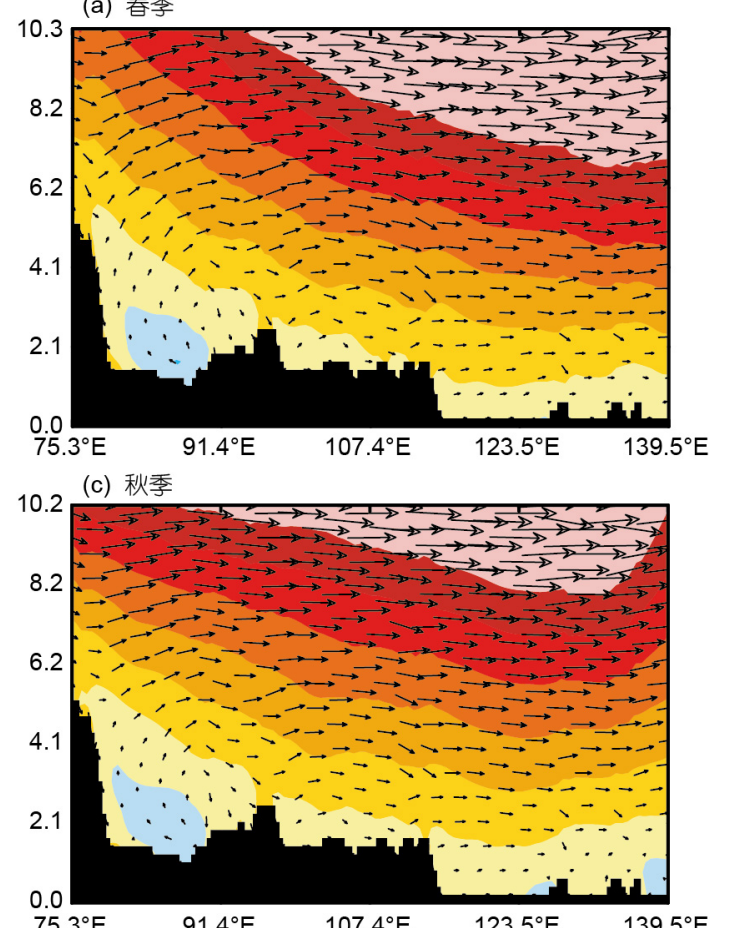

(b) 夏季

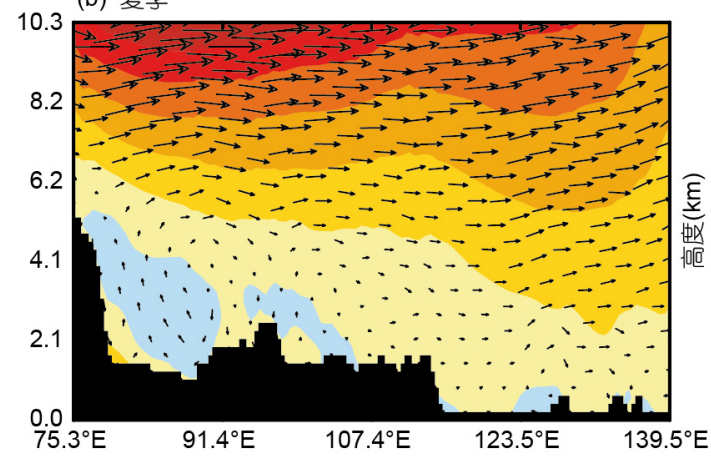

(d) 冬季

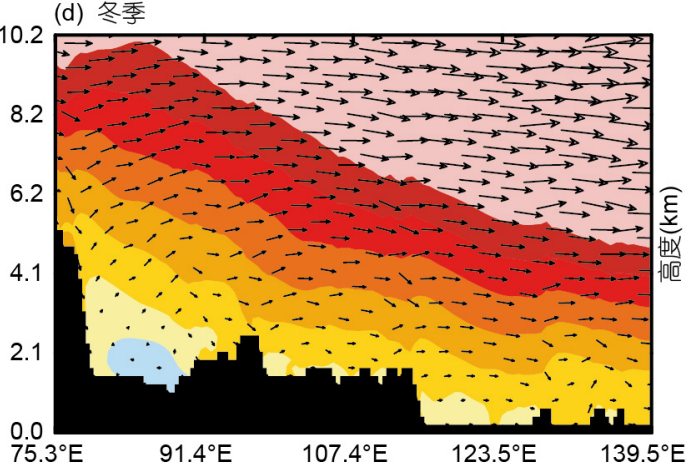



图 $102007 \sim 2011$ 年不同季节 $42^{\circ} \mathrm{N}, 75.3 \sim 120.2^{\circ} \mathrm{E}$ 的 $U$ 分量及其 $U$ 分量和 $w$ 分量的合成风向


图 112007 2011年不同季节TD和GD地区沙尘释放和传输的季节变化特征

正值代表沙尘对该地区沙尘含量的贡献为正, 负值代表沙尘对该地区沙尘含量的贡献为负; 单位: $\mathrm{g}\left(\mathrm{m}^{2} \mathrm{season}\right)^{-1}$

尘对东亚沙尘沉降区的贡献均大于TD地区. 两大 沙尘源区的沙尘传输在春季达到最大, GD沙尘传输
的季节变化趋势为 $-24.8 \mathrm{~g}\left(\mathrm{~m}^{2} \text { season }\right)^{-1}$, 占沙尘起沙的 $35.1 \%$. TD沙尘传输的季节变化趋势仅占沙尘起沙 
的 $25.4 \%$. Han 等 (2004)模拟了 2002 年东亚春季沙尘 的远距离输送过程, 其研究结果表明, 东亚两大沙 源地约有 $23 \%$ 的沙尘粒子悬浮在大气中或进行远距 离传输, 与本文的模拟结果相似. 在夏季, TD地区 的季节起沙变化趋势 $\left(54.3 \mathrm{~g}\left(\mathrm{~m}^{2} \text { season }\right)^{-1}\right)$ 大于 $\mathrm{GD}$ 地区 $\left(45.3 \mathrm{~g}\left(\mathrm{~m}^{2} \text { season }\right)^{-1}\right)$, 但两者的沙尘传输季节变化趋势 基本一致, 约为 $-14 \mathrm{~g}\left(\mathrm{~m}^{2} \text { season }\right)^{-1}$, 说明 GD沙尘的传输 能力要高于TD. GD起沙的季节变化趋势在秋季和冬 季均比TD要大, 沙尘传输能力也强, 沙尘传输的季节 变化趋势约为 $-11 \mathrm{~g}\left(\mathrm{~m}^{2} \text { season }\right)^{-1}$.

为了更直观地认识 $\mathrm{TD}$ 和 GD的沙尘传输过程, 图 12给出了 2007 2011年不同季节东亚地区沙尘传输通 量的空间分布特征. 在 $30^{\circ} \sim 45^{\circ} \mathrm{N}$ 范围内包括中国北部 地区、日本和韩国等地均不同程度地受到两大沙漠 的影响. 从图中可以发现, 不同季节GD地区的沙尘传 输通量明显大于TD地区, 其高值区向东南方向扩展至 京津冀地区 $\left(\right.$ 约 $\left.250 \mathrm{~g}\left(\mathrm{~m}^{2} \mathrm{~s}\right)^{-2}\right)$. 在起沙量最大的春季, 其 高值区向东南方向扩展至京津冀地区 $\left(\right.$ 约 $\left.250 \mathrm{~g}\left(\mathrm{~m}^{2} \mathrm{~s}\right)^{-1}\right)$.
在夏季, 沙尘传输与春季相比较弱, GD沙尘传输通量 的高值中心减弱至 $200 \mathrm{~g}\left(\mathrm{~m}^{2} \mathrm{~s}\right)^{-1}$, 到达北京地区的沙尘 传输通量约 $100 \mathrm{~g}\left(\mathrm{~m}^{2} \mathrm{~s}\right)^{-1}$. 在秋、冬季节, 沙尘传输通 量进一步减小, 但GD地区在向东向南方向仍存在一 定的传输能力, 传输通量最高达 $170 \mathrm{~g}\left(\mathrm{~m}^{2} \mathrm{~s}\right)^{-1}$. 从图 9 和 10 中可以明显看出两大沙源区传输差异的原因, 当大 量的 TD沙尘被扬起后, 由于周围山脉的阻挡以及 $\mathrm{TD}$ 高空风速较弱, TD沙尘不容易传输. 只有当沙尘垂直 抬升至 $5 \mathrm{~km}$ 以上的高度, 沙尘才能进入西风急流开始 远距离输送. GD近地面地区的风速较小, 盛行风向为 西风或西北风, 而GD上空正好位于南北两支气流的 汇合处, 春季和冬季 $500 \mathrm{hPa}$ 风速可高达 $20 \mathrm{~m} \mathrm{~s}^{-1}$ 之上. 此 外, 冷空气频繁沿西北路径或偏北路径影响GD地区, 也使得该地区产生区域性大风天气(Zhang B等, 2008). 因此, 该地区虽然起沙量小, 但GD沙尘在垂直方向强 烈混合的影响下会抬升到较高的高度, 并在强西风的 作用下使大量GD沙尘更容易向东南或者东北方向传 输, 对京津冀等发达地区甚至整个东亚地区的沙尘贡
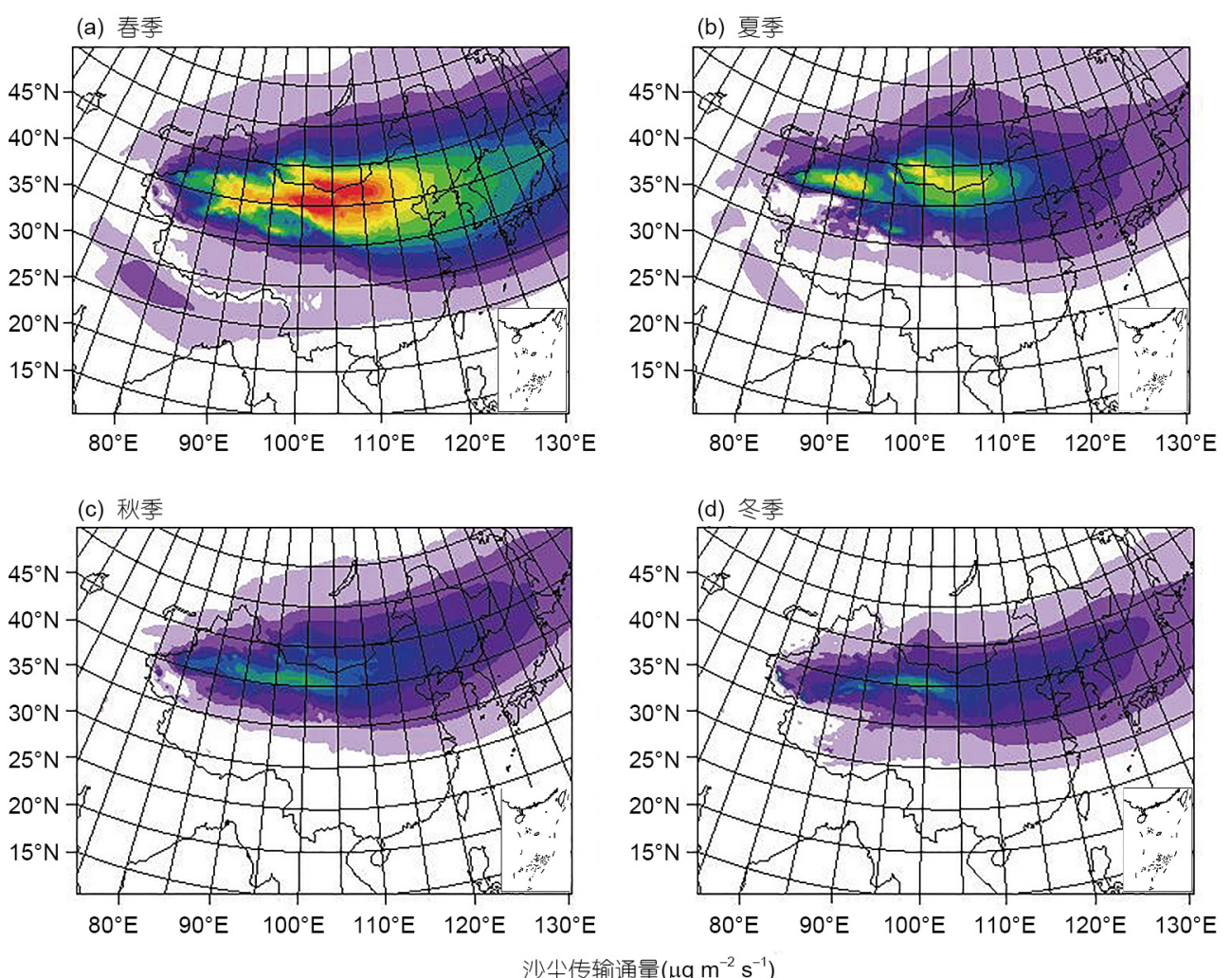

沙尘传输通量 $\left(\mu \mathrm{g} \mathrm{m}^{-2} \mathrm{~s}^{-1}\right)$

图 12 2007 2011年不同季节东亚地区沙尘传输通量的空间分布特征 
献最大. 需要注意的是, 夏季西风急流北跳至青藏高 原以北(最北可达 $44^{\circ} \mathrm{N}$ )(Zhang Y C 等, 2008), TD和 GD 的主导风向均为东风(TD地区东风风速偏大, 最高可 达 $25 \mathrm{~m} \mathrm{~s}^{-1}$ ), 从而导致夏季沙尘的东向传输能力比春季 弱. TD地区的部分沙尘甚至开始南向传输, 进而被抬 升至青藏高原北坡(Huang等, 2007; Chen等, 2013).

由于西风带的影响, GD区沙尘不可避免的会叠 加TD沙尘的影响. 因此, 本文给出了2007 2011不同 季节塔克拉玛干沙漠和戈壁沙漠右侧(图1两个红色 方框的右侧边)的沙尘向外流出通量的垂直分布特征 (图13). 为了讨论春季GD沙尘可能叠加了多少 TD区 输送而来的沙尘这一问题, 我们用红实线代表 GD和 $\mathrm{TD}$ 沙尘向右输送通量的差值. 从图中可以发现, 不 同高度 $(2 \sim 12 \mathrm{~km})$ 的GD沙尘在春季的向右输送通量均 高于 TD沙尘, 且在 $2 \mathrm{~km}$ 处有一个明显的高值区 (约为 $478 \mu \mathrm{g} \mathrm{m}^{-3}$ ). 由此说明, 即使 GD地区叠加了部分 TD输 送而来的沙尘粒子, 春季GD区依然表现出十分强劲的 沙尘向外传输能力, 且在低层大气(2 4km高度)表现 尤为明显. 在秋、冬季节也是如此, GD沙尘向右输送 通量在 $2 \mathrm{~km}$ 处有一个明显的高值区, 2 4km GD沙尘向 右输送通量远大于 TD沙尘. 在 $4 \mathrm{~km}$ 以上 $\mathrm{GD}$ 和 $\mathrm{TD}$ 沙尘 向右输送通量的数值基本一致, 我们认为该高度范围 内GD地区的大部分沙尘可能是TD沙尘抬升到一定高 度后, 进入西风急流开始远距离输送到GD所导致的, 但这个高度沙尘的输送通量的数值远小于低层输送 通量. 结合图 12 中 TD 和GD沙尘输送通量的分布和数 值大小, 我们均可认为 TD沙尘只有当抬升到 $4 \mathrm{~km}$ 以上 才可以进行远距离输送, 且该高度的沙尘输送通量较 小 (在春季约为 $124 \mu \mathrm{g} \mathrm{m}^{-3}$ ). GD沙尘更有利于在 $4 \mathrm{~km}$ 以 下的低层传输, 对东亚内陆地区的沙尘浓度贡献更大.

\subsection{TD和GD地区的沙尘沉降}

沙尘沉降过程分为干沉降和湿沉降两个部分. 从 图14中可以看出, 沙尘的干沉降量与沙尘起沙量有直 接关系. 在 TD和GD地区, 沙尘沉降过程主要以干沉降 为主, 季节平均的干沉降量大约在 $10 \sim 60 \mathrm{~g} \mathrm{~m}^{-2}$. 春、夏 季的沙尘干沉降大于秋、冬季, 其中以春季最大. 在 春季, 沙尘干沉降量在 TD和GD出现明显的大值区域, 高值中心可达 $50 \mathrm{~g} \mathrm{~m}^{-2}$ (图14). 在秋季和冬季, 干沉降主 要发生在起沙量大的GD地区, 沉降量约为 $10 \sim 20 \mathrm{~g} \mathrm{~m}^{-2}$. 图15给出了东亚地区沙尘湿沉降的空间分布特征. 沙
尘湿沉降主要是由该地的沙尘含量和降水量共同决 定. 四个季节的沙尘湿沉降最大值区均位于TD区域, 主要以春、夏季为主, 沙尘湿沉降约为 $4 \mathrm{~g} \mathrm{~m}^{-2}$, 仅为干 沉降量的 $1 / 10$, 秋季次之 (沙尘湿沉降约为 $1.5 \mathrm{~g} \mathrm{~m}^{-2}$ ), 冬 季最少 (沙尘湿沉降约为 $0.6 \mathrm{~g} \mathrm{~m}^{-2}$ ). GD地区的沙尘湿 沉降均小于 TD地区. 在春季和夏季, GD沙尘的湿沉 降量约为 $2 \mathrm{~g} \mathrm{~m}^{-2}$. 而在起沙量和降水量都小的冬季, 沙 尘的湿沉降量接近于 0 . Han等(2004)的模拟结果也发 现, 东亚沙尘源区以及附近地区主要以干沉降过程为 主, 大约 $71 \%$ 的沙尘在干沉降过程中重新沉降到地表, 湿沉降作用仅占 $6 \%$, 且对粗粒子 $(>2 \mu \mathrm{m})$ 的沉降效率更 为明显.

\section{5 结论与展望}

本文利用新一代高性能的WRF-Chem模式研究了 2007 2011年东亚地区两大沙源塔克拉玛干沙漠(TD) 和戈壁沙漠(简称为 $\mathrm{GD}$ )沙尘的起沙、传输和沉降过 程. 从模式验证结果中可以发现, WRF-Chem模式可以 很好再现TD和GD沙尘的空间分布特征及其季节变化 规律, 但模式模拟的夏季沙源地沙尘 $\mathrm{AOD}$ (尤其是 TD 地区)比卫星反演的略高. 近地面 $10 \mathrm{~m}$ 风速的模拟误差 以及GOCART起沙模块不能很好描述沙尘释放通量 的季节变化特征可能是导致AOD季节变化模拟误差 的主要因素. 为了解决这一问题, 我们将在未来的工 作中利用地基激光雷达观测网的长时间序列资料, 改 进和发展适用于东亚地区起沙的参数化方案, 进而提 高数值模式对东亚沙尘的模拟性能.

完整的沙尘生命史包括了沙尘的起沙、传输和 沉降过程. 本文利用数值模拟结果对比和分析了 $\mathrm{TD}$ 和 GD地区不同季节沙尘的起沙、传输和沉降过程, 研究 结果表明, TD和GD两大沙尘源区的地形、海拔高度 以及热力、动力条件的不同导致了沙尘释放、抬升 高度以及沙尘远距离运输等方面的差异. 文中着重强 调了GD沙尘对整个东亚地区沙尘贡献的重要性. 主 要研究结果如下:

(1) 沙尘释放. TD和 $\mathrm{GD}$ 是东亚地区两个最大的沙 源区. TD的起沙能力显著高于 $\mathrm{GD}$, 是东亚地区最大的 起沙源地, 春季沙尘释放通量为 $70.54 \mathrm{Tg} \mathrm{a}^{-1}$, 可占东亚 地区起沙的 $42 \%$. TD地区在不同季节沙尘释放比例不 均匀性较高, 春季最高, 夏、秋、冬季次之. GD地区 的起沙能力比TD地区弱, 二者差异在夏季最为显著, 


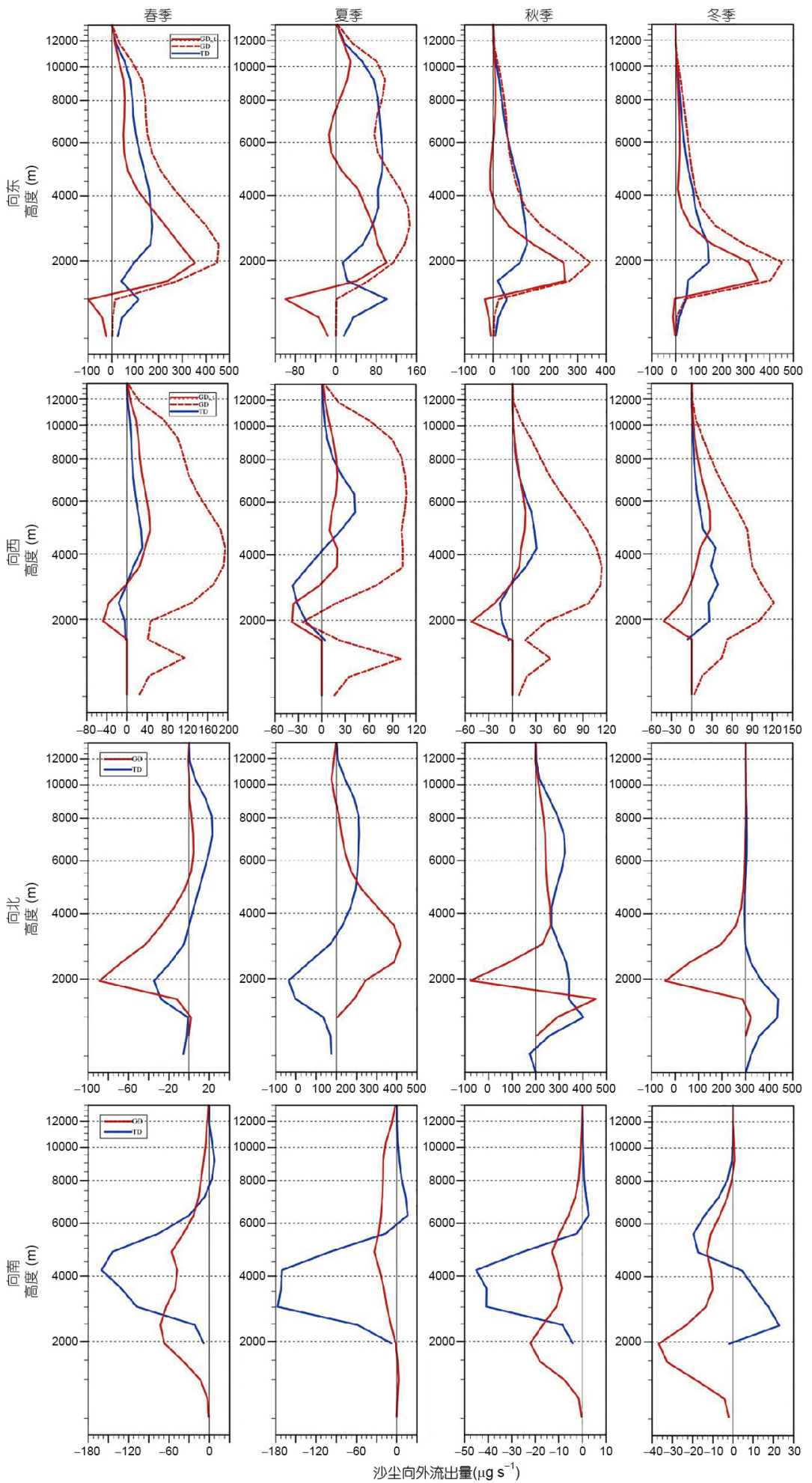

图 132007 2011不同季节塔克拉玛干沙漠和戈壁沙漠右侧(图 1 两个红色方框的右侧边)的沙尘向外流出通量 $\left(\mu \mathrm{gs}^{-1}\right)$ 的垂 直分布特征

正(负)值代表沙尘气溶胶向东(西)传输的通量. 蓝实线和红虚线分别代表了 TD和GD沙尘向右侧的输送通量; 红实线代表GD和TD沙尘向右 输送通量的差值 

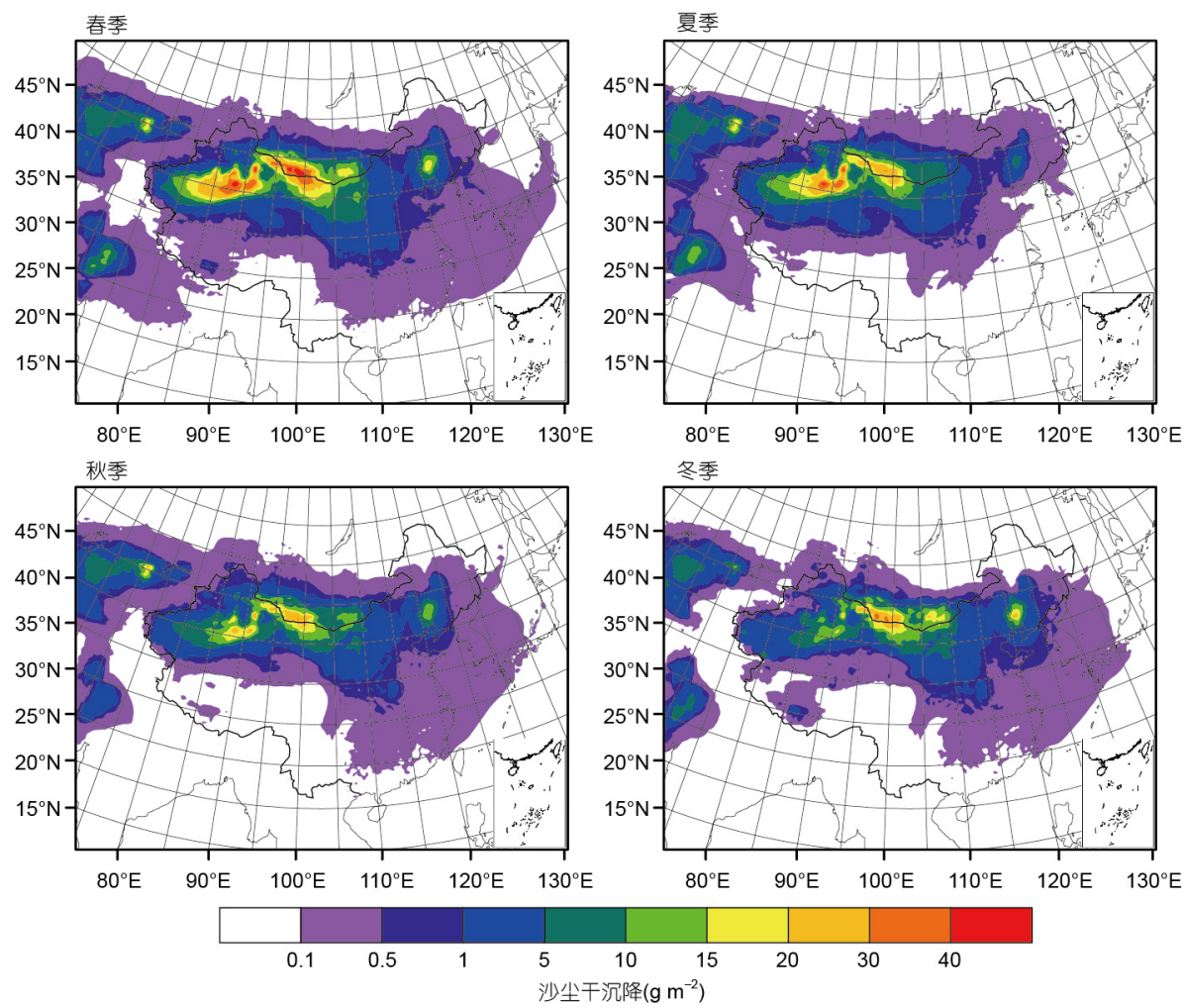

图 142007 2011年不同季节东亚地区沙尘干沉降的空间分布特征
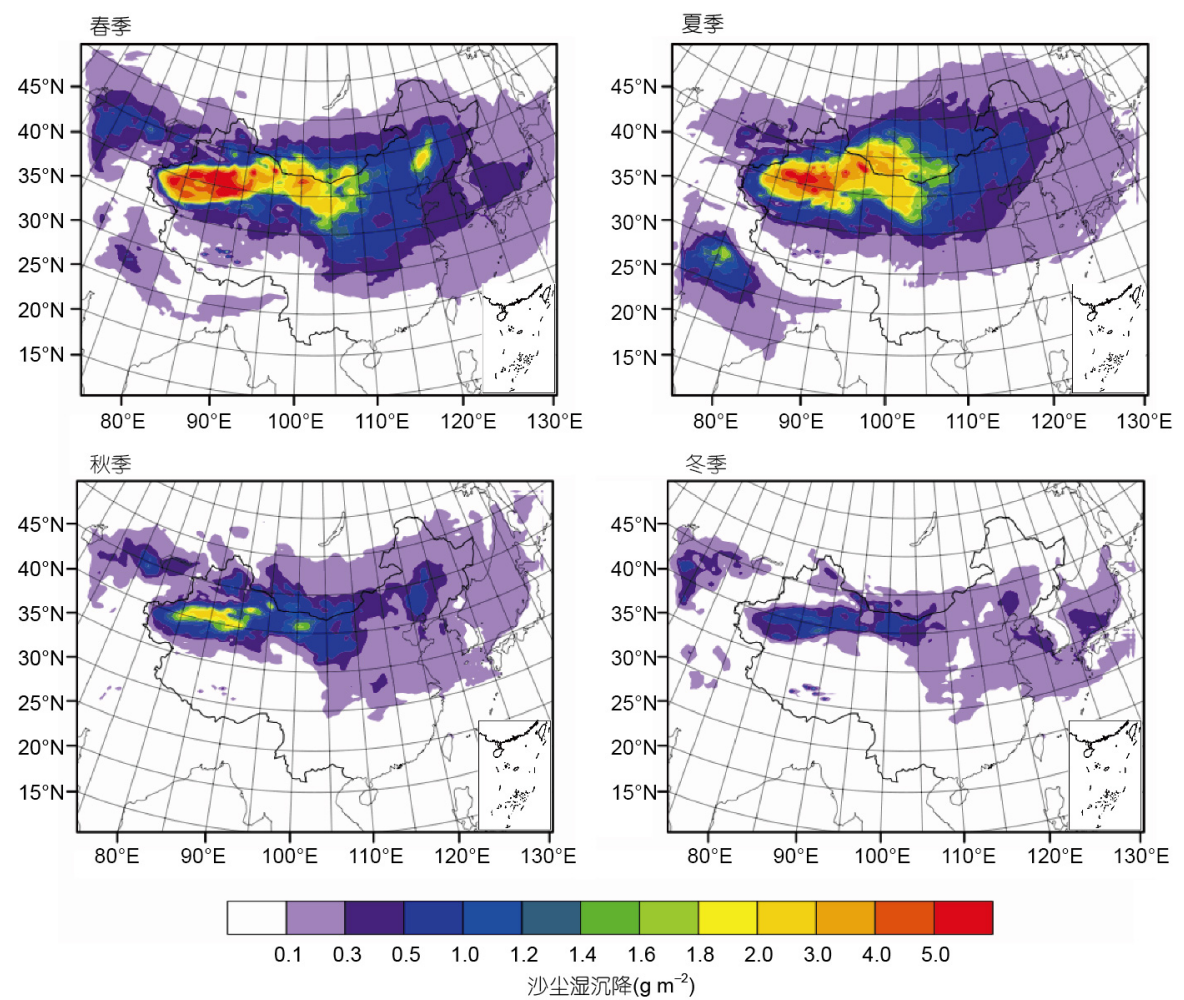

图 152007 2011年不同季节东亚地区沙尘湿沉降的空间分布特征 
沙尘释放通量可相差 $18 \mathrm{Tga}^{-1}$.

(2) 沙源区沙尘的垂直结构. TD和GD地区的起沙 情况与该地上空的沙尘含量存在着一定的不一致. 尽 管与 TD相比, GD的起沙能力相对较弱, 但GD地区更 容易将沙尘抬升至高空, 尤其在夏季, GD地区8 10km 沙尘浓度与 $3 \mathrm{~km}$ 以下沙尘浓度的比值可高达 $11 \%$. 其 主要原因在于, GD地区温度梯度小, 垂直方向混合强 烈, 有利于沙尘的向上抬升. 此外, GD上空受西风急 流的影响更大, 且频繁受到沿西、西北路径或偏北路 径冷空气系统的袭击, 导致GD高空风速大, 强烈的对 流混合导致高空的动量下传, 进一步加剧GD沙尘的 向上抬升.

(3) 沙尘传输. 在春季, 约有 $25 \%$ 的 TD沙尘和 $35 \%$ 的GD沙尘进行远距离传输. 在夏季, 约有 $23 \%$ 的TD沙 尘和 $31 \%$ 的GD沙尘进行远距离输送. 具体来说, GD地 区地势平坦, 近地面盛行西风和西北风, 高空受西风 急流的影响大, 有利于沙尘的远距离传输, 是对整个 东亚地区沙尘贡献最大的沙源区. TD地区三面环山, 地面风多以东风为主, 沙漠上空风速较小, 因此该地 区并不利于沙尘传输, 大部分沙尘在扬起之后又以干 沉降和湿沉降的过程重新沉降到地面, 只有当沙尘抬 升高度大于 $5 \mathrm{~km}$ 时才可被西风携带进行远距离传输.

(4) 沙尘沉降. 沙尘源区主要以沙尘干沉降为主, 高值中心可达 $50 \mathrm{gm}^{-2}$. 湿沉降主要取决于该地的沙尘 含量和降水量, TD地区沙尘的湿沉降最大, 湿沉降为 干沉降的十分之一. 在降水充沛的地区, 沙尘的干、 湿沉降量相当, 约为 $1 \sim 5 \mathrm{~g} \mathrm{~m}^{-2}$.

在后面的工作中, 我们将基于WRF-Chem模式进 行敏感性试验, 分别讨论仅有TD和GD沙尘情况下TD 和GD沙尘对东亚沙尘的贡献, 更为定量化的探讨不同 季节不同高度下的TD和GD沙尘对东亚沙尘的影响.

\section{参考文献}

康丽泰, 陈思宇. 2017. 中国北方一次沙尘天气过程的数值模拟. 中 国沙漠, 37: 321-331

申彦波, 沈志宝, 杜明元. 2005. 风蚀起沙的影响因子及其变化特征. 高原气象, 24: 611-616

Belly P Y. 1964. Sand movement by wind. US Army Coastal Eng Res Tech Memo. 1-38

Cavazos-Guerra C, Todd M C. 2012. Model simulations of complex dust emissions over the Sahara during the West African monsoon onset.
Adv Meteor, 2012: 1-17

Chen F, Dudhia J. 2001. Coupling an advanced land surface-hydrology model with the Penn State-NCAR MM5 modeling system. Part I: Model implementation and sensitivity. Mon Weather Rev, 129: 569-585

Chen S Y, Huang J P, Kang L T, Wang H, Ma X, He Y, Yuan T, Yang B, Huang Z, Zhang G. 2017. Emission, transport, and radiative effects of mineral dust from the Taklimakan and Gobi Deserts: Comparison of measurements and model results. Atmos Chem Phys, 17: 2401-2421

Chen S Y, Huang J P, Qian Y, Ge J M, Su J. 2014a. Effects of aerosols on autumn precipitation over Mid-eastern China. J Trop Meteorol, 20: 242-250

Chen S Y, Huang J P, Zhao C, Qian Y, Leung L R, Yang B. 2013. Modeling the transport and radiative forcing of Taklimakan dust over the Tibetan Plateau: A case study in the summer of 2006. J Geophys Res-Atmos, 118: 797-812

Chen S Y, Zhao C, Qian Y, Leung L R, Huang J P, Huang Z W, Bi J R, Zhang W, Shi J S, Yang L, Li D S, Li J X. 2014b. Regional modeling of dust mass balance and radiative forcing over East Asia using WRF-Chem. Aeolian Res, 15: 15-30

Cheng T, Chen H, Gu X, Yu T, Guo J, Guo H. 2012. The inter-comparison of MODIS, MISR and GOCART aerosol products against AERONET data over China. J Quant Spectrosc Ra, 113: 2135-2145

Diner D J, Hodos R A, Davis A B, Garay M J, Martonchik J V, Sanghavi S V, von Allmen P, Kokhanovsky A A, Zhai P. 2012. An optimization approach for aerosol retrievals using simulated MISR radiances. Atmos Res, 116: 1-14

Diner D J, Martonchik J V, Kahn R A, Pinty B, Gobron N, Nelson D L, Holben B N. 2005. Using angular and spectral shape similarity constraints to improve MISR aerosol and surface retrievals over land. Remote Sens Environ, 94: 155-171

Eguchi K, Uno I, Yumimoto K, Takemura T, Shimizu A, Sugimoto N, Liu Z. 2009. Trans-pacific dust transport: Integrated analysis of NASA/CALIPSO and a global aerosol transport model. Atmos Chem Phys, 9: 3137-3145

Fast J D, Gustafson Jr. W I, Easter R C, Zaveri R A, Barnard J C, Chapman E G, Grell G A, Peckham S E. 2006. Evolution of ozone, particulates, and aerosol direct radiative forcing in the vicinity of Houston using a fully coupled Meteorology-Chemistry-Aerosol Model. J Geophys Res, 111: D21305

Fu Q, Thorsen T J, Su J, Ge J M, Huang J P. 2009. Test of Mie-based single-scattering properties of non-spherical dust aerosols in radiative flux calculations. J Quant Spectrosc Ra, 110: 1640-1653

Ge J M, Huang J P, Xu C P, Qi Y L, Liu H Y. 2014. Characteristics of Taklimakan dust emission and distribution: A satellite and reanalysis field perspective. J Geophys Res-Atmos, 119: 11772-11783 
Ge J M, Su J, Ackerman T P, Fu Q, Huang J P, Shi J S. 2010. Dust aerosol optical properties retrieval and radiative forcing over northwestern China during the 2008 China-U.S. joint field experiment. J Geophys Res, 115: D00K12

Grell G A, Peckham S E, Schmitz R, McKeen S A, Frost G, Skamarock W C, Eder B. 2005. Fully coupled "online" chemistry within the WRF model. Atmos Environ, 39: 6957-6975

Ginoux P, Chin M, Tegen I, Prospero J M, Holben B, Dubovik O, Lin S J. 2001. Sources and distributions of dust aerosols simulated with the GOCART model. J Geophys Res, 106: 20255-20273

Ginoux P, Prospero J, Torres O, Chin M. 2004. Long-term simulation of global dust distribution with the GOCART model: Correlation with North Atlantic oscillation. Environ Model Softw, 19: 113-128

Gong S L, Zhang X Y, Zhao T L, McKendry I G, Jaffe D A, Lu N M. 2003. Characterization of soil dust aerosol in China and its transport and distribution during 2001 ACE-Asia: 2. Model simulation and validation. J Geophys Res, 108: 4262

Han Z, Ueda H, Matsuda K, Zhang R, Arao K, Kanai Y, Hasome H. 2004. Model study on particle size segregation and deposition during Asian dust events in March 2002. J Geophys Res, 109: D19205

Hanna S R, Yang R, Yin X. 2000. Evaluations of numerical weather prediction (NWP) models from the point of view of inputs required by atmospheric dispersion models. Int J Environ Pollut, 14: 98

Hong S Y, Noh Y, Dudhia J. 2006. A new vertical diffusion package with an explicit treatment of entrainment processes. Mon Weather Rev, 134: 2318-2341

Huang J P, Fu Q, Su J, Tang Q, Minnis P, Hu Y, Yi Y, Zhao Q. 2009. Taklimakan dust aerosol radiative heating derived from CALIPSO observations using the $\mathrm{Fu}$-Liou radiation model with CERES constraints. Atmos Chem Phys, 9: 4011-4021

Huang J P, Fu Q, Zhang W C, Wang X, Zhang R, Ye H, Warren S G. 2011. Dust and black carbon in seasonal snow across northern China. Bull Amer Meteorol Soc, 92: 175-181

Huang J P, Guan X, Ji F. 2012. Enhanced cold-season warming in semiarid regions. Atmos Chem Phys, 12: 5391-5398

Huang J P, Lin B, Minnis P, Wang T, Wang X, Hu Y, Yi Y, Ayers J K. 2006a. Satellite-based assessment of possible dust aerosols semi-direct effect on cloud water path over East Asia. Geophys Res Lett, 33: L19802

Huang J P, Minnis P, Chen B, Huang Z, Liu Z, Zhao Q, Yi Y, Ayers J K. 2008. Long-range transport and vertical structure of Asian dust from CALIPSO and surface measurements during PACDEX. J Geophys Res, 113: D23212

Huang J P, Minnis P, Lin B, Wang T, Yi Y, Hu Y, Sun-Mack S, Ayers K. 2006b. Possible influences of Asian dust aerosols on cloud properties and radiative forcing observed from MODIS and CERES. Geophys
Res Lett, 33: L06824

Huang J P, Minnis P, Yi Y, Tang Q, Wang X, Hu Y, Liu Z, Ayers K, Trepte C, Winker D. 2007. Summer dust aerosols detected from CALIPSO over the Tibetan Plateau. Geophys Res Lett, 34: L18805

Huang J P, Wang T H, Wang W, Li Z, Yan H. 2014. Climate effects of dust aerosols over East Asian arid and semiarid regions. J Geophys Res-Atmos, 119: 11398-11416

Huang Z W, Huang J P, Bi J R, Wang G Y, Wang W C, Fu Q, Li Z Q, Tsay S C, Shi J S. 2010. Dust aerosol vertical structure measurements using three MPL lidars during 2008 China-U.S. joint dust field experiment. J Geophys Res, 115: D00K15

Huneeus N, Schulz M, Balkanski Y, Griesfeller J, Kinne S, Prospero J, Bauer S, Boucher O, Chin M, Dentener F, Diehl T, Easter R, Fillmore D, Ghan S, Ginoux P, Grini A, Horowitz L, Koch D, Krol M C, Landing W, Liu X, Mahowald N, Miller R, Morcrette J J, Myhre G, Penner J E, Perlwitz J, Stier P, Takemura T, Zender C. 2010. Global dust model intercomparison in AeroCom phase I. Atmos Chem Phys Discuss, 10: 23781-23864

Jia R, Liu Y Z, Chen B, Zhang Z J, Huang J P. 2015. Source and transportation of summer dust over the Tibetan Plateau. Atmos Environ, 123: $210-219$

Kahn R A, Gaitley B J. 2015. An analysis of global aerosol type as retrieved by MISR. J Geophys Res-Atmos, 120: 4248-4281

Kain J S. 2004. The kain-fritsch convective parameterization: An update. J Appl Meteorol, 43: 170-181

Kanayama S, Yabuki S, Zeng F L, Liu M Z, Shen Z B, Liu L C, Yanagisawa F, Abe O. 2005. Size-dependent geochemical characteristics of Asian dust. J Meteorol Soc Jpn, 83A: 107-120

Kang L T, Huang J P, Chen S Y, Wang X. 2016. Long-term trends of dust events over Tibetan Plateau during 1961-2010. Atmos Environ, 125: $188-198$

Kim J. 2008. Transport routes and source regions of Asian dust observed in Korea during the past 40 years (1965-2004). Atmos Environ, 42: 4778-4789

Marticorena B, Bergametti G. 1995. Modeling the atmospheric dust cycle: 1. Design of a soil-derived dust emission scheme. J Geophys Res, 100: 16415

Martonchik J V, Diner D J, Crean K A, Bull M A. 2002. Regional aerosol retrieval results from MISR. IEEE Trans Geosci Remote Sens, 40: $1520-1531$

Martonchik J V, Diner D J, Kahn R, Gaitley B, Holben B N. 2004. Comparison of MISR and AERONET aerosol optical depths over desert sites. Geophys Res Lett, 31: L16102

Morrison H, Curry J A, Khvorostyanov V I. 2005. A new double-moment microphysics parameterization for application in cloud and climate models. Part I: Description. J Atmos Sci, 62: 1665-1677 
Nakano T, Yokoo Y, Nishikawa M, Koyanagi H. 2004. Regional Sr-Nd isotopic ratios of soil minerals in northern China as Asian dust fingerprints. Atmos Environ, 38: 3061-3067

Pye K. 1989. Aeolian Dust and Dust Deposites. 2nd ed. San Diego: Academic Press

Qian Y, Gong D Y, Fan J W, Leung L R, Bennartz R, Chen D L, Wang W. 2009. Heavy pollution suppresses light rain in China: Observations and modeling. J Geophys Res, 114: D00K02

Stauffer D R, Seaman N L. 1990. Use of four-dimensional data assimilation in a limited-area mesoscale model. Part I: Experiments with synoptic-scale data. Mon Weather Rev, 118: 1250-1277

Shao Y, Wyrwoll K H, Chappell A, Huang J, Lin Z, McTainsh G H, Mikami M, Tanaka T Y, Wang X, Yoon S. 2011. Dust cycle: An emerging core theme in Earth system science. Aeolian Res, 2: $181-204$

Shao Y P, Yang Y, Wang J J, Song Z X, Leslie L M, Dong C H, Zhang Z H, Lin Z H, Kanai Y, Yabuki S, Chun Y. 2003. Northeast Asian dust storms: Real-time numerical prediction and validation. J Geophys Res, 108: 4691-4710

Su J, Huang J P, Fu Q, Minnis P, Ge J M, Bi J R. 2008. Estimation of Asian dust aerosol effect on cloud radiation forcing using Fu-Liou radiative model and CERES measurements. Atmos Chem Phys, 8: 2763-2771

Sun J, Zhang M, Liu T. 2001. Spatial and temporal characteristics of dust storms in China and its surrounding regions, 1960-1999: Relations to source area and climate. J Geophys Res, 106: 10325-10333

Tesfaye M, Sivakumar V, Botai J, Mengistu Tsidu G. 2011. Aerosol climatology over South Africa based on 10 years of Multiangle Imaging Spectroradiometer (MISR) data. J Geophys Res, 116: D20216

Uno I, Yumimoto K, Shimizu A, Hara Y, Sugimoto N, Wang Z, Liu Z, Winker D M. 2008. 3D structure of Asian dust transport revealed by CALIPSO lidar and a 4DVAR dust model. Geophys Res Lett, 35: L06803

Wang J, Xu X G, Henze D K, Zeng J, Ji Q, Tsay S C, Huang J P. 2012. Top-down estimate of dust emissions through integration of MODIS and MISR aerosol retrievals with the GEOS-Chem adjoint model. Geophys Res Lett, 39: L08802

Wang Q Z, Zhuang G S, Huang K, Liu T N, Lin Y F, Deng C R, Fu Q, Fu J S, Chen J K, Zhang W J, Yiming M. 2016. Evolution of particulate sulfate and nitrate along the Asian dust pathway: Secondary transformation and primary pollutants via long-range transport. Atmos Res,
169: $86-95$

Wang X, Huang J P, Zhang R D, Chen B, Bi J R. 2010. Surface measurements of aerosol properties over northwest China during ARM China 2008 deployment. J Geophys Res, 115: D00K27

Weaver C J, Ginoux P, Hsu N C, Chou M D, Joiner J. 2002. Radiative forcing of Saharan dust: GOCART model simulations compared with ERBE Data. J Atmos Sci, 59: 736-747

Yue X, Wang H, Liao H, Fan K. 2010. Direct climatic effect of dust aerosol in the NCAR Community Atmosphere Model Version 3 (CAM3). Adv Atmos Sci, 27: 230-242

Yue X, Liao H, Tang J P. 2013. Simulation of the direct radiative effect of mineral dust and sea salt aerosols in a doubled Carbon dioxide climate. Atmos Ocean Sci Lett, 6: 343-348

Zhao C, Chen S, Leung L R, Qian Y, Kok J F, Zaveri R A, Huang J. 2013. Uncertainty in modeling dust mass balance and radiative forcing from size parameterization. Atmos Chem Phys, 13: 10733-10753

Zhao C S, Dabu X, Li Y. 2004. Relationship between climatic factors and dust storm frequency in Inner Mongolia of China. Geophys Res Lett, 31: L01103

Zhao C, Liu X, Leung L R, Johnson B, McFarlane S A, Gustafson Jr. W I, Fast J D, Easter R. 2010. The spatial distribution of mineral dust and its shortwave radiative forcing over North Africa: Modeling sensitivities to dust emissions and aerosol size treatments. Atmos Chem Phys, 10: 8821-8838

Zhang B, Tsunekawa A, Tsubo M. 2008. Contributions of sandy lands and stony deserts to long-distance dust emission in China and Mongolia during 2000-2006. Glob Planet Change, 60: 487-504

Zhang J, Reid J S. 2010. A decadal regional and global trend analysis of the aerosol optical depth using a data-assimilation grade over-water MODIS and Level 2 MISR aerosol products. Atmos Chem Phys, 10: 10949-10963

Zhang X Y, Gong S L, Zhao T L, Arimoto R, Wang Y Q, Zhou Z J. 2003. Sources of Asian dust and role of climate change versus desertification in Asian dust emission. Geophys Res Lett, 30: 2272

Zhang Y C, Takahashi M, Guo L. 2008. Analysis of the East Asian subtropical westerly jet simulated by CCSR/NIES/FRCGC coupled climate system model. J Meteorol Soc Jpn, 86: 257-278

Zender C S, Bian H, Newman D. 2003. Mineral Dust Entrainment and Deposition (DEAD) model: Description and 1990s dust climatology. J Geophys Res, 108: 4416 